\title{
LA INFLUENCIA DEL CLUB ATLETISMO JOAQUÍN BLUME EN LA SOCIEDAD SEGOVIANA DURANTE MÁS DE 50 AÑOS
}

\author{
Jorge Martín Martín \\ Estudiante de Doctorado en la Universidad de Valladolid (España) \\ j.marge90@gmail.com
}

Fecha recepción: septiembre 2020

Fecha de aceptación: Noviembre 20202

http://doi.org/10.15366/citius2020.13.2.006

\section{Resumen:}

El objetivo de este trabajo de investigación ha sido dar una visión sobre las primeras manifestaciones de atletismo en la ciudad de Segovia (Castilla y León), a través de la creación del Club Atlético Joaquín Blume (C.A.J. Blume). En este artículo se pretende rescatar la historia del club, recuperando la iniciativa de ciudadanos anónimos, que ha sido la base para el funcionamiento de este durante más de 50 años. Este trabajo ha sido elaborado a través de siete entrevistas, a siete presidentes diferentes del C.A.J. Blume (Antonio Pinillos, Tomás Lorenzo, Fernando Fuentetaja, Jaime Gila, Emiliano del Caño, Tomás Lorenzo y Gustavo Gómez), con la finalidad de conocer desde su perspectiva, cómo era la situación atlética en cada una de las etapas, a la vez que analizar la evolución del club. El espíritu de equipo y el ambiente familiar por el que se ha conocido siempre a la entidad, y su filosofía, de no solo de formar atletas, sino también personas, han sido las bases para el mantenimiento del mismo. En la actualidad el club tiene convenios de colaboración con el Ayuntamiento de Segovia y la Diputación de Segovia para el desarrollo del atletismo en la ciudad y provincia; cuenta con una Junta Directiva con responsabilidades administrativas y deportivas y, a la vez dispone de entrenadores para todas las categorías y especialidades atléticas.

Palabras Clave: Club Atlético Joaquín Blume, atletismo, historia de vida, historia de tiempo presente, valores, Segovia y liderazgo social.

\section{Title: THE JOAQUÍN BLUME ATHLETICS CLUB'S INFLUENCE ON THE SEGOVIAN SOCIETY OVER MORE THAN 50 YEARS.}

\begin{abstract}
:
The objective of this investigation project has been to share a vision of the first athletic events in the city of Segovia (Castilla y León), through the creation of the Joaquín Blume Athletic Club (C.A.J. Blume). This article seeks to restore the history of the club, retrieving the initiative of anonymous citizens, which has been the basis for its functioning throughout more than 50 years. This project is made up of seven interviews with seven different C.A.J. Blume presidents (Antonio Pinillos, Tomás Lorenzo, Fernando Fuentetaja, Jaime Gila, Emiliano del Caño, Tomás Lorenzo y Gustavo Gómez), for the purpose of getting to know, from their points of view, the athletic situation in each one of the stages, as well as analysing the evolution of the club. The team's spirit and the family environment that the entity has always been known for, and its philosophy of not only forming athletes but also people, have been the foundations for its longevity. Currently, the club has collaborative agreements with the Town Hall of Segovia and also the County Council of Segovia in order to develop Athletics in the city and the province. It has a Board of Directors with administrative and sporting responsibilities, as well as coaches for all the athletic categories and specialities.
\end{abstract}

Key words: Club Atlético Joaquín Blume, Athletics, life story, current period History research, Segovia and social leadership 


\section{Objeto de Estudio}

En el presente trabajo se pretende conocer y descubrir la historia de vida del C.A.J. Blume e identificar la influencia de este en la sociedad segoviana, a través de las diferentes perspectivas de siete presidentes que han pasado por la entidad en diferentes épocas.

Por otro lado, se analizará la evolución del atletismo en la ciudad Segovia desde el año 1966 hasta el 2020, a fin de conocer como el C.A.J. Blume ha podido influir en el contexto de una provincia pequeña como Segovia. Se pretende conocer si los éxitos deportivos, los eventos y la filosofía del club han servido de influencia en la práctica atlética de la sociedad segoviana.

\section{Objetivos del proyecto}

\subsection{Principal}

Conocer la historia de vida del C.A.J. Blume y el posible rol de liderazgo social que ha podido desempeñar tanto en la ciudad de Segovia, como en la provincia, así como la presencia de los valores que este club promueve.

\subsection{Secundarios}

Conocer la situación del atletismo en Segovia antes de la creación del C.A.J. Blume desde la perspectiva de Antonio Pinillos y como ha sido la evolución mediante la perspectiva de los otros presidentes.

Analizar el nivel de liderazgo social que ha tenido el C.A.J. Blume en su entorno social, en los diferentes momentos de su historia.

Comprender la importancia del C.A.J. Blume, en la creación de diferentes eventos deportivos en la ciudad de Segovia.

Conocer cuales era los objetivos que se propuso el club y como han ido siendo percibidos los mismos con el paso de los años.

\section{Metodología de investigación.}

Las circunstancias y la ubicación temporal del objeto de estudio de este trabajo me llevan a identificarlo como una investigación sobre la Historia del Tiempo Presente (HTP) que Martínez Gorroño, M.E. (1996) representa como la etapa de la Historia Contemporánea que cuenta con la circunstancia de que su reconstrucción se puede obtener por medio de fuentes vivas. Ellas ofrecen al investigador una información cualitativa de los hechos vividos que no es posible conocer por el uso de fuentes escritas. Soto Gamboa, A. (2004) afirma que el investigador de la HPT tiene la oportunidad de observar y evaluar las mentalidades, la percepción de los entrevistados sobre la trama y sus propias vivencias.

Por ello, el diseño metodológico usado para esta investigación partió, en principio, del objetivo de realizar la historia de vida del C.A.J. Blume, que es el objeto de estudio. Para ello, según las normas de la formación metodológica recibida en la Universidad Autónoma de Madrid por este investigador, se procedió a identificar y categorizar las fuentes orales primarias del estudio, que han sido algunos de los presidentes del C.A.J. Blume: Antonio Pinillos (1966-1969), Tomás Lorenzo (1971-1974), Fernando Fuentetaja (1979-1981), Jaime Gila (1983-1986), Emiliano del Caño (1993-1997), Tomás Lorenzo (1998-2011) y Gustavo Gómez (2019-2020). A todas las fuentes orales categorizadas como primarias se les realizaron entrevistas semiestructuradas de final abierto, bajo las propuestas por Hammer \& Wildasky, (1990). Se 
estructuró previamente un guion de las mismas, modificando las cuestiones a cada caso concreto, aunque con contenidos comunes con la finalidad de poder triangular la información recabada.

Por otra parte, el proceso de aproximación al objeto de estudio se efectuó a partir de la búsqueda de documentos gráficos y fuentes hemerográficas rescatadas de varios orígenes: artículos de prensa realizados por diferentes medios, difundidos por internet, fotografías de la época cedidas por diferentes atletas, actas del club, recortes de periódico, entrevistas realizadas por diferentes medios... Todos estos documentos fueron objeto de un exhaustivo análisis documental para reunir información sobre las diferentes etapas de los presidentes entrevistados, con el fin de construir la trayectoria deportiva y social del C.A.J. Blume y rescatar la historia de vida de la entidad deportiva que es el objetivo de este proyecto. Por otro lado, la información y los datos extraídos de estas fuentes hemerográficas también ha mostrado información sobre la repercusión e influencia que tiene el club en la sociedad segoviana.

\section{Contexto social y atlético antes de la creación del club}

Segovia es una ciudad y municipio español en la parte meridional de la comunidad autónoma de Castilla y León, capital de la provincia del mismo nombre. La ciudad se encuentra ubicada en las cercanías de la Sierra de Guadarrama. La morfología del terreno es ondulada y la ciudad se encuentra alrededor de los 1.000 metros de altitud.

Antes del año 1966 Segovia no contaba con federación de atletismo. Las únicas pruebas atléticas que se disputaban en Segovia eran organizadas por el Frente de Juventudes ${ }^{1} \mathrm{y}$ eran carreras a pie dirigidas en aquella época por Juan Bermejo. En aquel momento la ciudad no contaba con pistas de atletismo, el lugar de entrenamiento era el Pinarillo. ${ }^{2}$ "No había ninguna estructura, la primera federación se crea después de la creación del club y por iniciativa nuestra». ${ }^{3}$

\section{La creación y estructuras del club a lo largo de su historia}

La creación del club surgió por tres atletas segovianos que residían en Madrid: Antonio Pinillos, Agustín Fernández y Pedro Sacristán. Los fines de semana entrenaban en Segovia donde no había posibilidad de hacer atletismo. «Cuando entrenábamos en la zona del Pinarillo surgía gente que quería entrenar con nosotros.» ${ }^{4}$

En el mes de septiembre del año 1966 estos tres atletas se reúnen en un bar de José Zorrilla, con la finalidad de crear el club. Allí se decidió el nombre "Club Atlético Joaquín Blume”. La primera Junta Directiva la formaban: Agustín Fernández, Pedro Sacristán, Félix del Caz, Mariano de Diego y César. También se nombró al primer presidente, Antonio Pinillos.

«Pensamos en un nombre para el club. En el momento de la creación era acertado, luego después, pensamos que no había sido el más adecuado, ya que, Joaquín Blume era un Gimnasta, no atleta. ${ }^{5}$

\footnotetext{
${ }^{1}$ El Frente de Juventudes: fue un organismo político-administrativo creado en España en 1940, como sección juvenil autónoma de Falange España. El Frente de Juventudes fue creado para el encuadramiento y adoctrinamiento político de los jóvenes españoles, además de ser un pilar indiscutible del régimen de la dictadura franquista para la educación y formación de la juventud española. Entre las actividades que organizaban destacaban los eventos deportivos de baloncesto, balonmano, atletismo, natación...

2 Pinarillo: Es un parque situado al suroeste de Segovia, muy conocido por los segovianos, por ser un área con alto valor natural, paisajístico e histórico. En se pueden encontrar diferentes rutas donde practicar senderismo, ciclismo o carreras a pie. La vegetación que más abunda en la zona es el Pino y, como consecuencia se deriva el nombre que recibe.

${ }^{3}$ De entrevista con Antonio Pinillos Grande, presidente, entrenador y atleta del club desde el año 1966 hasta 1969. La entrevista fue realizada el día 1 de agosto del 2019 y refrendada el día 15 de agosto del 2019.

${ }^{4}$ De entrevista con Antonio Pinillos ya citada.

${ }^{5}$ De entrevista con Antonio Pinillos ya citada.
} 
«Hubo problemas para hacer el club por la edad, los tres mayores teníamos 25 años, 24 años y 22 años, y éramos los cabecillas del tema, el resto tenían entre 14 y 15 años.»

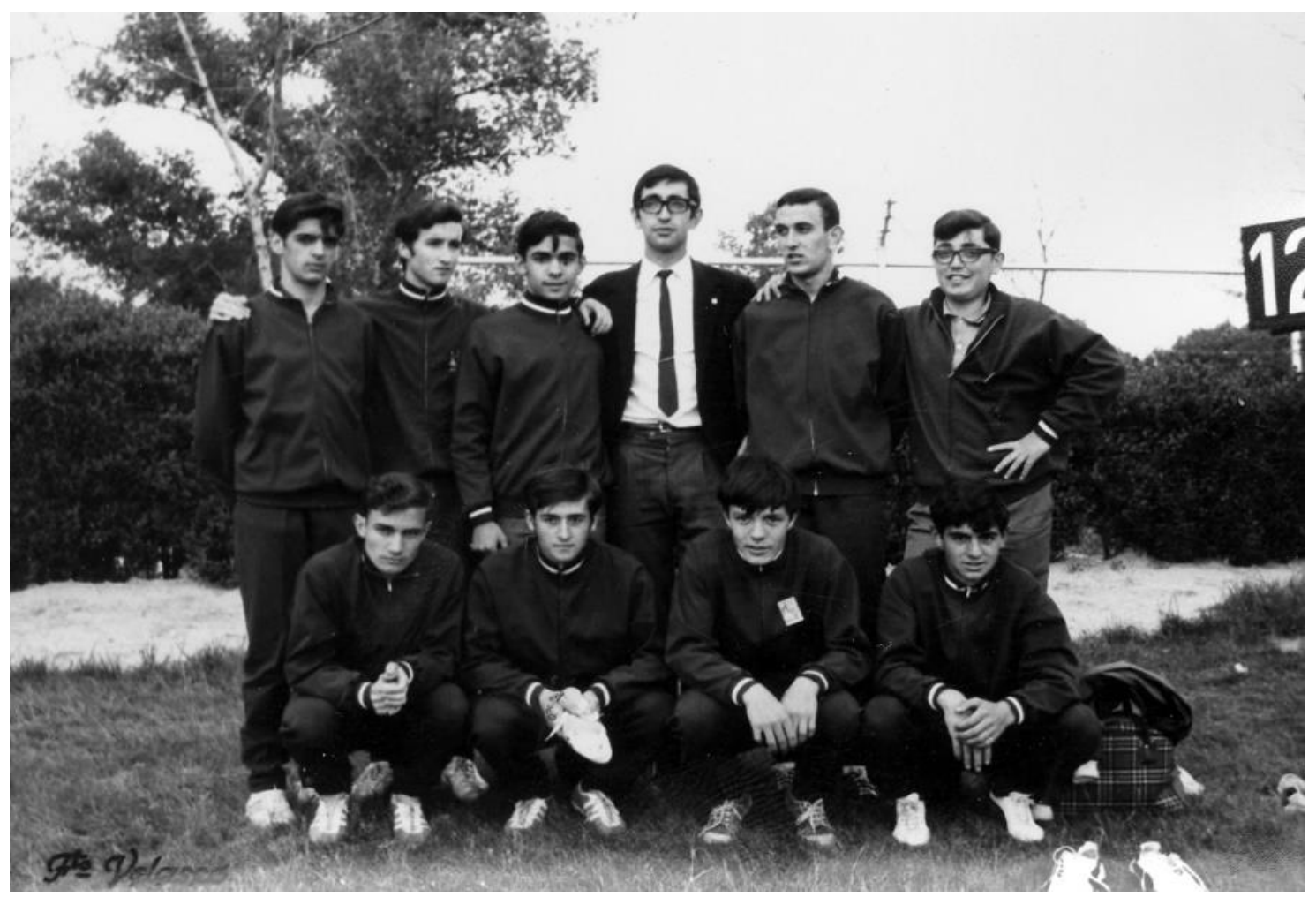

Ilustración 1: Primera prueba del Club Atlético Joaquín Blume en pista. Año 1967. Fila de abajo: Félix, Isidro, José y Julio Pinillos. Fila de arriba: Gilberto, Mariano, César, Pinillos; Castrillo y Alfonso.

A finales del 69 Antonio se fue a Valladolid por temas laborales, por tanto, se creó una nueva junta directiva y se nombró presidente a Isaac Sastre. Por diversos motivos, en el año 1970 Isaac fue destituido. Entró en la presidencia Tomás Lorenzo a principios del año 1971. «Tomás Lorenzo, presidente; Cesar Castrillo, tesorero; Luis María Bravo, secretario y José Ignacio de la Calle, vocal.» ${ }^{7}$

A finales del año 1974, dejó la presidencia de Tomás Lorenzo y le relevó en el cargo Miguel Ángel Estévez hasta el año 78. Durante su mandato se crearon las primeras pistas de atletismo en Segovia, en el año 1974. El material de las mismas fue de tierra batida roja y este hecho colocó a la ciudad de Segovia en la vanguardia, a causa de que en aquella época era raro la ciudad que disponía de un recinto donde realizar atletismo. En el año 1979 llegó a la presidencia Fernando Fuentetaja y estuvo en ella hasta el año 1981. Sobre su conformación afirmaba: «Estaba: Iñaki, Orte, José Juan Álvarez y Calle. Y como técnico Isaac Sastre.» ${ }^{8}$

A Fernando le sustituyó José María del Prisco que fue presidente en el año 1982. Del año 1983 al 1987 en el cargo estuvo Jaime Gila.

\footnotetext{
${ }^{6}$ De entrevista con Antonio Pinillos ya citada.

${ }^{7}$ De entrevista con Tomás Lorenzo (Correspondiente a su primera etapa en la presidencia), presidente y atleta del club desde el año 1970 hasta 1973. La entrevista fue realizada el día 26 de septiembre del 2019 y refrendada el día 9 de octubre del 2019.

${ }^{8}$ De entrevista con Fernando Fuentetaja, presidente y atleta del club desde el año 1979 hasta 1981. La entrevista fue realizada el día 2 de noviembre del 2019 y refrendada el día 19 de noviembre del 2019.
} 
«Dado mi situación, que estaba en Ayllón y solo venía los fines de semana, no podría destacar a una o varias personas, ya que aprecio la labor de los que durante estos años ayudaron al club.»9

En el año 1988 el club estuvo comandado por Basilio García, en ese mismo año se inauguró en Segovia la pista de material sintético. Al año siguiente la entidad estuvo capitaneada por Francisco del Caño. Del 1990 al 1993 el club fue dirigido por una junta rectora, bajo la dirección de esta junta directiva se conmemoró el 25 aniversario del club en el año 1991 con una cena en la que se reunieron atletas de las diferentes épocas.

En 1993 llegó a la presidencia Emiliano del Caño, cuyo mandato duró hasta finales del año 1997.

«Víctor López Pastor (Secretario), José Ignacio de la Calle (Vocal), Alfonso Piedehierro (Vocal), Jaime Gila (Vocal), Fernando Fuentetaja (Vocal).» ${ }^{10}$

Le sustituyó en el cargo Tomás Lorenzo en el año 1998, durante su presidencia hubo varias Juntas Directivas, ya que conservó el cargo hasta su dimisión en el año 2011. Su presidencia coincidió con el incremento en su popularidad por la práctica de la carrera a pie. Y además en el año 2006 se llegó al 40 aniversario del club.

«En esta época estaba Isaac Sastre. Aunque no le gustaba, siempre ha estado presente, José María Cebrián, Alfonso Piedehierro, Fernando Cuesta, José Ignacio de la Calle, Ignacio de la Calle, Diego Cebrián y Pedro Lorenzo. Y hay más gente que se me olvida y que han ayudado. Todavía recuerdo las reuniones celebradas en el Bar Siboney de Fernando Fuentetaja.» ${ }^{11}$

El club no encontraba presidente y, por tanto, se creó una Junta Rectora dirigida por Isaac Sastre entre los años 2012 al 2016. En ese momento Isaac decidió tomar la presidencia hasta su repentino fallecimiento en el 2018.

Aquello supuso un gran problema para el club que estuvo varios meses sin presidente, hasta que a principios del año 2019 llegó a la presidencia Gustavo Gómez.

«El presidente: Gustavo Gómez de Andrés, el tesorero es Valentín Muñoz Cristóbal y el secretario es Raúl Calvo.» ${ }^{12}$

«En este momento yo entré a formar parte de la Junta directiva con funciones de secretario, con la finalidad de ayudar a Isaac con los papeles del club, mientras Fuencisla ejercía las funciones de tesorera.» 13

Por tanto, los datos que este apartado recupera compendian todos los presidentes que el C.A.J. Blume ha tenido a lo largo de sus más de 50 años de historia.

\footnotetext{
${ }^{9}$ De entrevista con Jaime Gila, presidente, entrenador y atleta del club desde el año 1983 hasta 1986. La entrevista fue realizada el día 28 de noviembre del 2019 y refrendada el día 9 de diciembre del 2019.

${ }^{10}$ De entrevista con Emiliano del Caño, presidente, entrenador y atleta del club desde el año 1993 hasta 1997. La entrevista fue realizada el día 2 de enero del 2020 y refrendada el día 10 de enero del 2020.

${ }^{11}$ De entrevista con Tomás Lorenzo (Correspondiente a su segunda etapa en la presidencia), presidente y atleta del club desde el año 1998 hasta 2011. La entrevista fue realizada el día 26 de septiembre del 2019 y refrendada el día 9 de octubre del 2019.

${ }^{12}$ De entrevista con Gustavo Gómez, presidente y atleta del club desde el año 2019 hasta 2020. La entrevista fue realizada el día 1 de noviembre del 2019 y refrendada el día 11 de noviembre del 2019.

${ }^{13}$ De entrevista con Gustavo Gómez ya citada.
} 


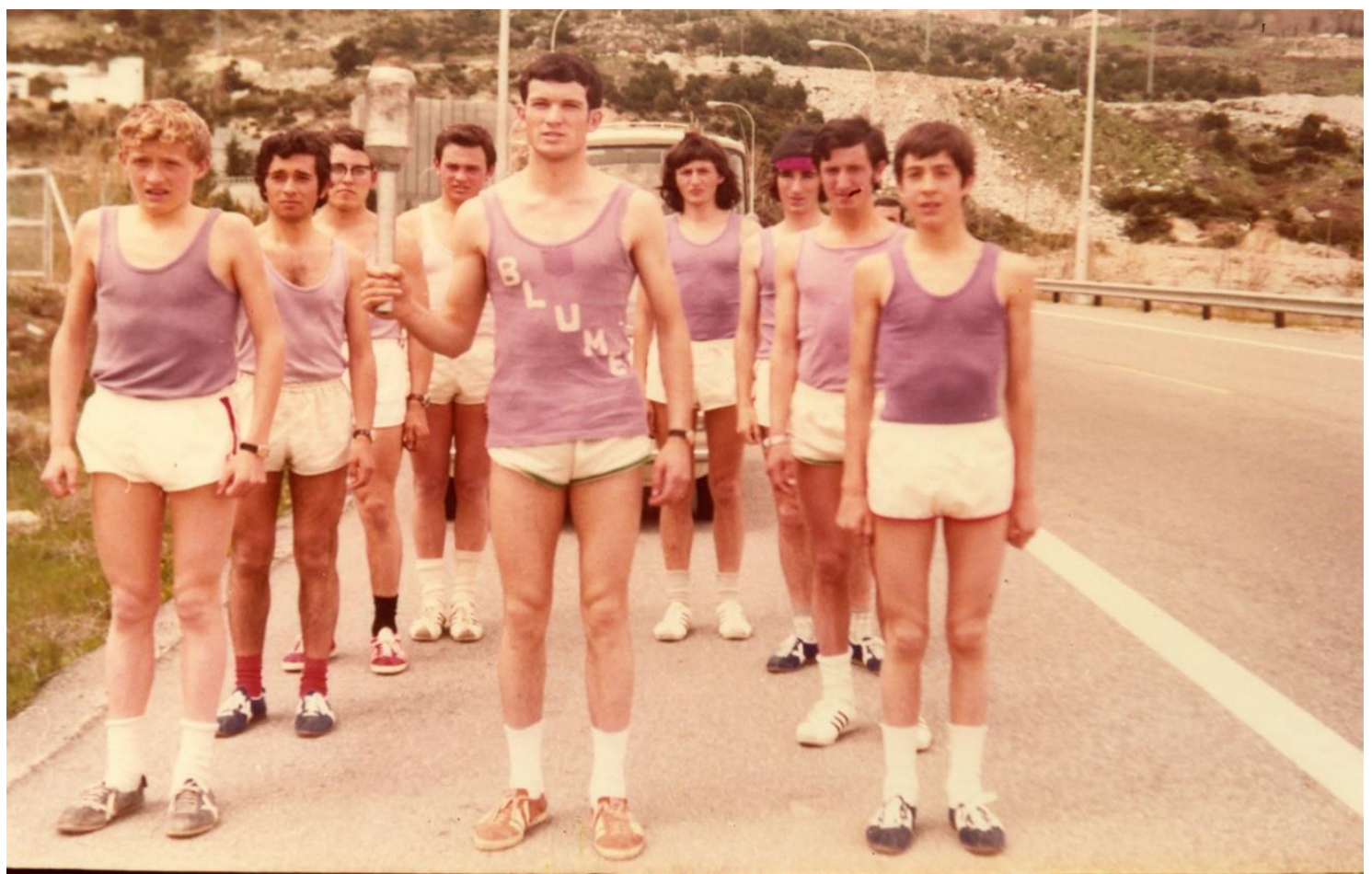

Ilustración 2: Año 1972 Relevo de la Antorcha de Juegos Sindicales organizados por Educación y Descanso. Salida del Túnel Madrid Segovia. Luis, Michel, Calle, Fernando, Barahona (portador de la Antorcha), José Joaquín, Alberto, Paulino y Francisco Guerra.

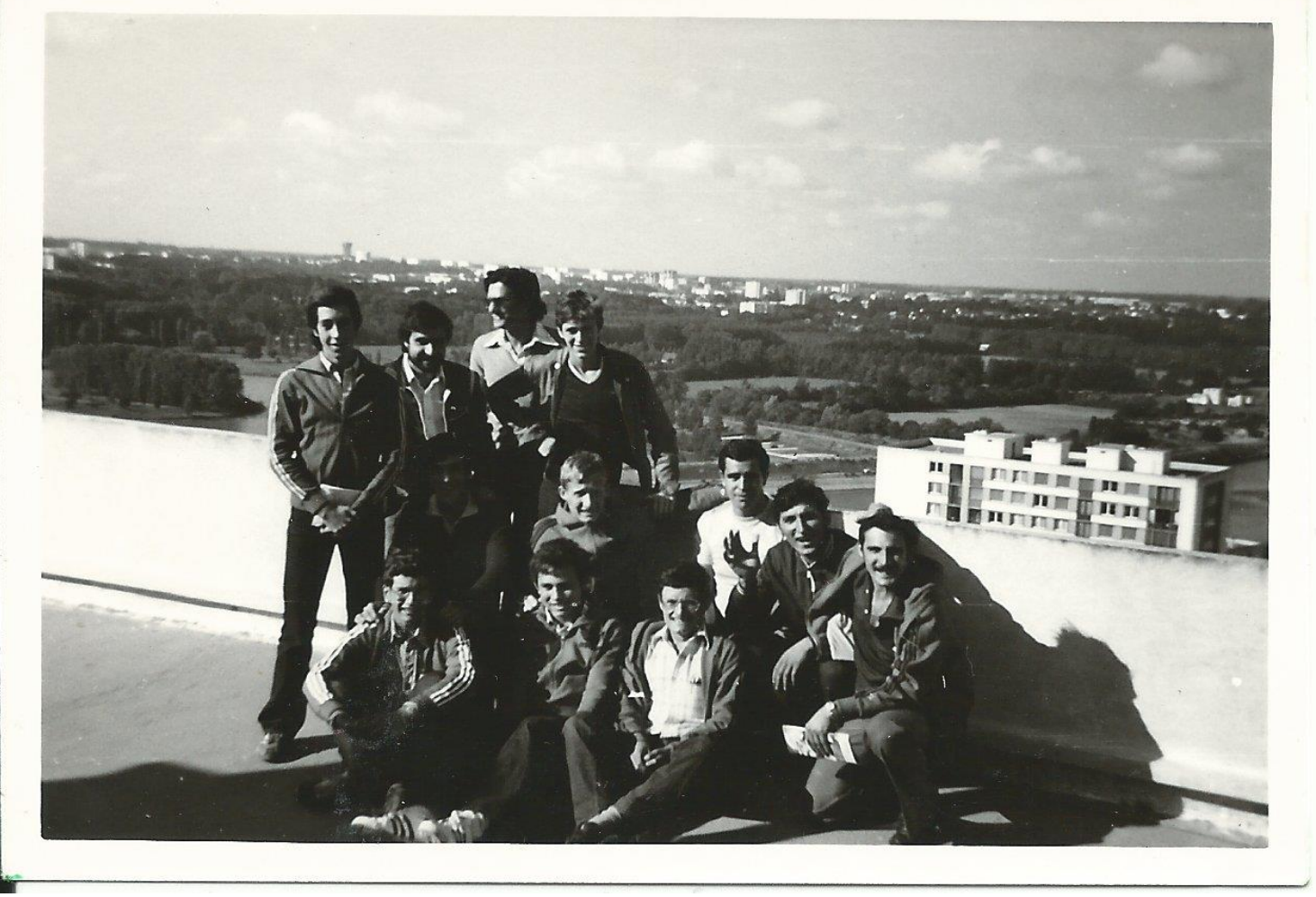

Ilustración 3: Año 1976. Atletas que acudieron por parte del C.A.J. Blume al intercambio en Tours (FR). Arriba: Paco Guerra, Juez de San Lorenzo, José Luis de Vicente, Paco Vázquez. Abajo: Javi Sáez, Luis Torrego, Fernando, Luis Cuesta, Nano, Mariano, Ajo, Isaac. 


\section{Objetivos del club desde 1966 hasta 2020}

En el año 1966 el presidente se puso como objetivo la práctica del atletismo en la ciudad de Segovia. El club comenzó con apenas 15 atletas y la única modalidad atlética que se realizaba era la carrera a pie.

«Todo esto se empezó corriendo porque no había otra forma, ya que no había otro tipo de pruebas que pudiéramos hacer.» ${ }^{14}$

En el año 1968 se comenzaron a practicar otras especialidades a la vez que se inscribían las primeras féminas.

Los objetivos del club analizados por cada uno de los presidentes en sus diferentes etapas son:

- Formar y crear atletas. "Preparar a los atletas tanto deportivamente, como aportarles conocimientos para la vida" 15

- Dar a conocer el atletismo a la sociedad segoviana. De lo citado por los presidentes se puede obtener la conclusión que la prensa segoviana difundía de forma ejemplar los resultados de sus atletas. "Gracias a los medios de comunicación la sociedad segoviana se enteraba de nuestros resultados, y, por tanto, de que había un club de atletismo en Segovia" ${ }^{\prime 6}$

- Seguir siendo un club familiar. Los entrevistados opinan, que el club promovía la amistad. Todos llegaban a la conclusión de que era un club de amigos unidos por la misma pasión. «El club era un club de amigos/as que nos gustaba mucho el atletismo, en el que convivíamos de forma magistral hombres y mujeres (hasta el año 1996).» ${ }^{17}$

- Acercar el atletismo a la gente de a pie por medio de pruebas atléticas. «Desde el año 1967 el C.A.J. Blume siempre ha organizado como mínimo un evento atlético por temporada.» ${ }^{18}$

Otro de los objetivos del club siempre ha sido crecer, llegar a más gente. Por eso se crearon sedes del club en diferentes pueblos de la provincia como: Cantimpalos, Riaza, Santiuste, Nava de la Asunción, Villacastín... Para ello fue muy importante la labor de varios monitores o entrenadores: Fernando Fuentetaja (Nava de la Asunción), Isaac Sastre (Segovia), Pedro Matarranz (Cantimpalos), Marcelino Casado (Nava de la Asunción), Jesús (Villacastín) Arturo (Riaza). Además de otros monitores que ayudaban con los atletas en etapas de formación.

«Lo más importante fue que se creó un cultivo que ha ido floreciendo.» ${ }^{19}$

\footnotetext{
${ }^{14}$ De entrevista con Antonio Pinillos ya citada.

${ }^{15}$ De entrevista con Fernando Fuentetaja ya citada.

${ }^{16}$ De entrevista con Tomás Lorenzo ya citada.

${ }^{17}$ De entrevista con Fernando Fuentetaja ya citada.

${ }^{18}$ De entrevista con Gustavo Gómez ya citada.

${ }^{19}$ De entrevista con Antonio Pinillos ya citada.
} 


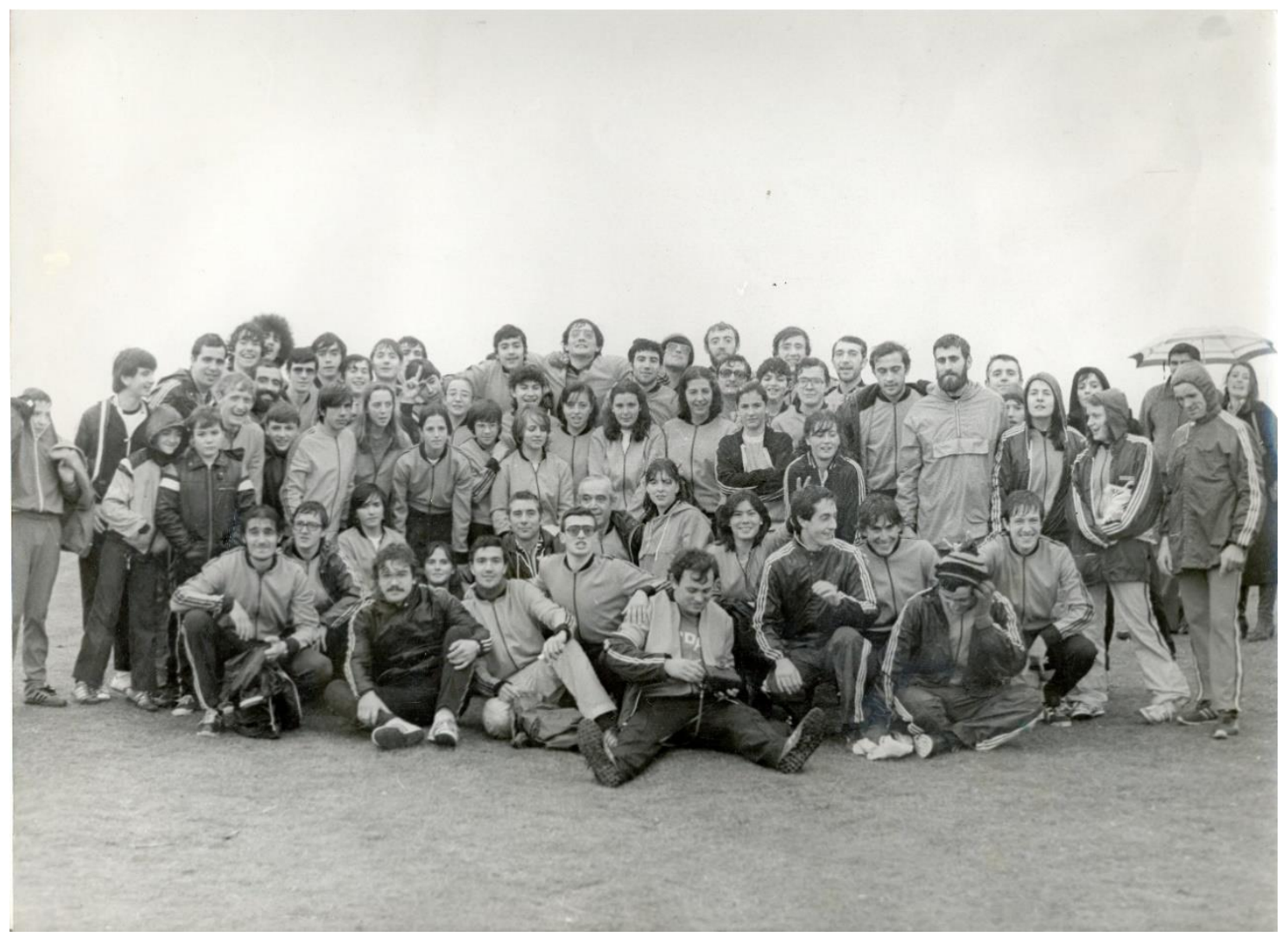

Ilustración 4: Club Atlético Joaquín Blume en el año 1980. Cross de Cantimpalos.

\section{Evolución de la entidad desde el año 1966 al 2020}

Los comienzos del club no fueron fáciles, a causa de que en el año 1966 la economía del país no era buena, por tanto, el club se hacía cargo de costear los viajes a los atletas, quienes rondaban los 14 años de edad, y por tanto no ganaban dinero por sí mismos. La solución que encontró Antonio Pinillos fue ir a escardar a cambio de un jornal.

«Los problemas del club, pues que no teníamos nada, ni presupuesto, ni patrocinadores, ¿cómo subsistimos? pues íbamos a trabajar al campo para faenas de escardar. Y con este dinero íbamos al Espinar a una carrera en la que daban dinero. Y con este dinero íbamos a Madrid a competir. ${ }^{20}$

Con aquel jornal se cubría el viaje para ir hasta el Espinar, donde se realizaba una prueba con premios en metálico. Y con el dinero obtenido se sufragaban los viajes a las competiciones del resto de atletas pertenecientes al club.

El lugar donde se acudía a competir era Madrid por motivos de número de competiciones, nivel competitivo de las mismas y mayor red de transportes autobús y tren. Antonio Pinillos, con solo 22 años, se montaba en el autobús e iba hasta Madrid como responsable de una veintena de atletas de entre 14 y 16 años.

En el año 1968 el C.A.J. Blume decidió que su creación había sido para hacer atletismo y no carrera a pie. Y, por tanto, dejaron de entrenar en la zona del Pinarillo, para asentarse en la explanada de Chamberí, donde había un campo de fútbol en muy malas condiciones. Es allí donde se empiezan a trabajar las especialidades atléticas. Para ello, debieron pintar las líneas de las calles con cal y llevar arena para que los saltadores de longitud no cayeran sobre la tierra.

${ }^{20}$ De entrevista con Antonio Pinillos ya citada. 
«Chamberi era un campo de "fútbol" con sus baches..., No había tierra firme prácticamente. Ahora imaginate correr un doscientos en esas condiciones. Las medidas eran aproximadas y las líneas las marcábamos con Cal. Por eso, para confirmar las marcas teníamos que ir a Madrid.» ${ }^{21}$

En el año 1968 llegaron las primeras féminas al club. Con ello se cumplía uno de los objetivos que se había propuesto la entidad, que era llevar el atletismo a la sociedad segoviana.

En el año 1971 llegó a la presidencia Tomás Lorenzo y uno de sus logros fue conseguir que el lugar de entrenamiento del club fueran las pistas de Baterías ${ }^{22}$, que eran de uso militar y estaban restringidas; pero a cambio de un alquiler dejaban entrenar allí a los atletas del C.A.J. Blume.

«Durante mi presidencia conseguimos el permiso de los militares, para utilizar las pistas de Baterías para entrenar y realizar alguna competición como: Campeonatos Provinciales de Pista y algún encuentro. ${ }^{23}$

Las competiciones en aquella época eran en Madrid por los mismos motivos que en la etapa anterior. Y al igual que Antonio, Tomás debió hacerse cargo de aproximadamente una veintena de atletas desde Segovia, hasta las pistas del Barrio de la Concepción de Madrid.

«Yo iba al cargo de los viajes que se realizaban desde Segovia hasta las pistas de atletismo de la Concepción con apenas 20 años. El volumen de atletas que solía llevar era de alrededor de la veintena y todos ellos de edades comprendidas entre los 13 y 14 años. Estos viajes se solían realizar en tren o en autobús.» ${ }^{24}$

Para acudir a las mismas había que realizar las inscripciones y en aquella época solo había estas dos alternativas. Por un lado, el correo postal, que implicaba escribir a máquina con una hoja de calco las inscripciones y luego una hoja era para el responsable que iba a esa prueba, y la otra hoja que se enviaba por correo postal a la Real Federación Española de Atletismo (RFEA). Por el otro, estaba la llamada telefónica y realizabas las inscripciones citando el nombre del atleta y la prueba a realizar.

«Las inscripciones las hacíamos a través de la telefónica, Para llegar había que subir hasta la plaza de los Huertos, esperar a que te dieran la llamada y hacer las inscripciones. Ya no te digo nada para hacer los cambios.» ${ }^{25}$

En el año 1973 se crearon en las inmediaciones de Chamberí ${ }^{26}$ unas pistas de atletismo de tierra batida roja, de seis calles, y con un pequeño graderío en la recta de llegadas. Esto provocó que Segovia se colocase en un lugar relevante con respecto a las instalaciones atléticas, a causa de que en aquel momento muy pocas ciudades de España contaban con unas pistas de atletismo. Para la construcción de las mismas tuvo mucho que ver el C.A.J. Blume.

\footnotetext{
${ }^{21}$ De entrevista con Antonio Pinillos ya citada.

${ }^{22}$ Baterías: es una base militar ubicada al norte de la ciudad de Segovia. En ella se instruyen a los suboficiales del Arma. Además, es donde se ubica la residencia del personal de tropa de la unidad, y los materiales de artillería comunes a las unidades, así como simuladores, modernos talleres y aulas donde se forman los técnicos superiores en Mecatrónica Industrial. También se forman en estas aulas a los técnicos de Administración de Sistemas Informáticos. Entre sus instalaciones deportivas destacaba su pista de escoria fina, cuya cuerda era de 447 metros.

${ }^{23}$ De entrevista con Tomás Lorenzo (Correspondiente a su primera etapa en la presidencia) ya citada.

${ }^{24}$ De entrevista con Tomás Lorenzo (Correspondiente a su primera etapa en la presidencia) ya citada.

${ }^{25}$ De entrevista con Tomás Lorenzo (Correspondiente a su primera etapa en la presidencia) ya citada.

${ }^{26}$ Chamberí: era un barrio en el extrarradio de la ciudad de Segovia, donde se encontraba un campo de fútbol de tierra en pésimas condiciones. En la actualidad en esa ubicación se encuentra el IES La Albuera y viviendas pertenecientes al Barrio del Carmen.
} 


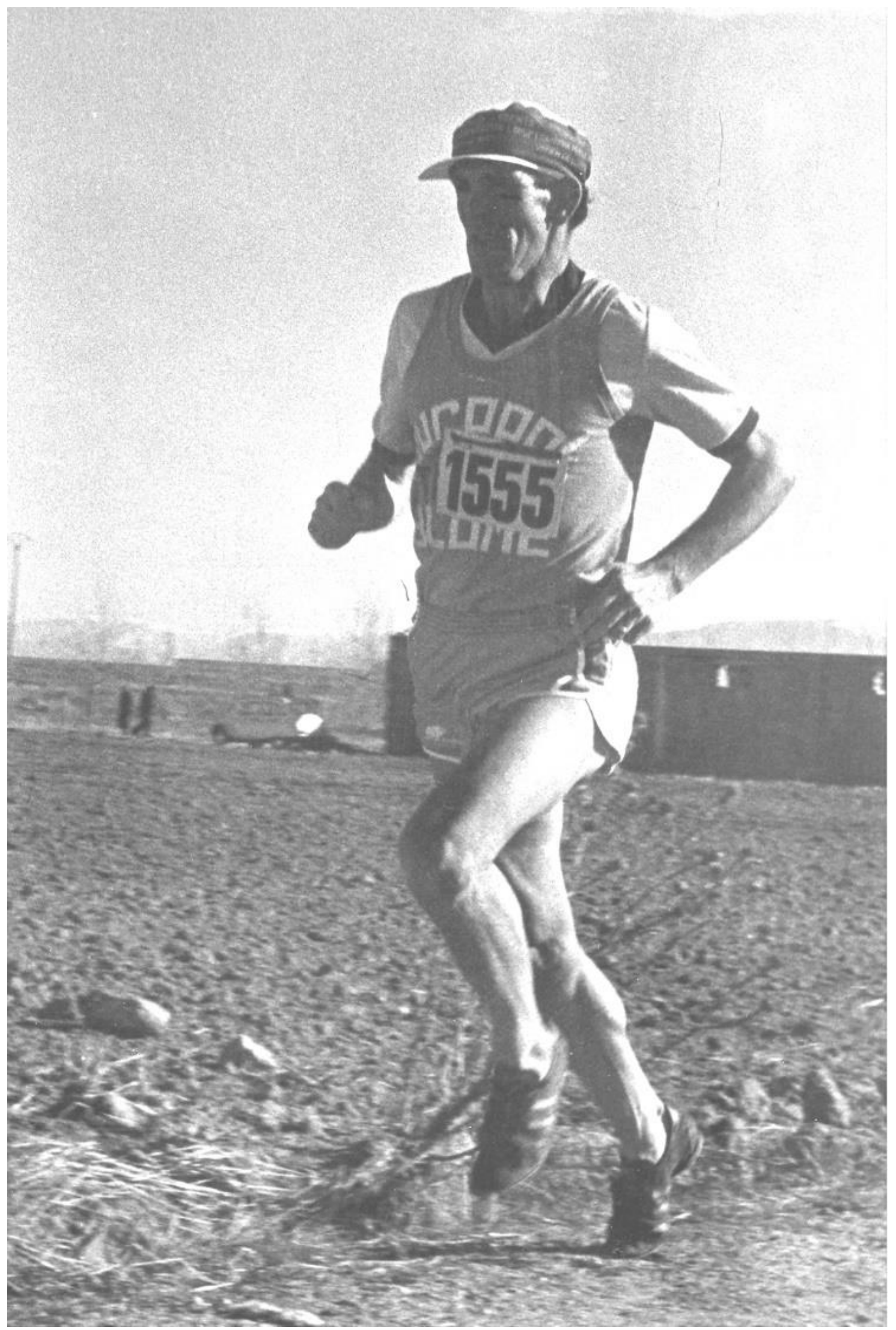

Ilustración 5: Agustín Fernández. Cross de Cantimpalos. Año 1980.

Citius, Altius, Fortius Volumen 13 ne 2. Noviembre, 2020. ISऽH. 2340-9886.

http://doi.org/10.15366/eitius2020.13.2 
$\mathrm{Al}$ comienzo de los 80 el C.A.J. Blume había experimentado un importante crecimiento. Rondaba el centenar de los atletas en la capital y su fama había llegado hasta algunos pueblos de la provincia. Como explicaba Fernando Fuentetaja, el club en ese momento se expandió y, aunque su epicentro eran las pistas de atletismo de Chamberí, el club había creado sedes en: Cantimpalos, Riaza, Nava de la Asunción y Villacastín. En todos estos pueblos, la media era de una treintena de atletas. El club ayudaba económicamente a estos atletas con las competiciones y también les facilitaba material deportivo como: Chándal, ropa de competición y a los deportistas más destacados o constantes, zapatillas de clavos, muy valoradas en aquella época.

En el año 1983 se celebró en Segovia una prueba de $20 \mathrm{~km}$ marcha en ruta, que fue organizada por el C.A.J. Blume con la finalidad de que la sociedad segoviana conociera otra disciplina atlética, a la vez que veía marchar a algunos de los marchadores más destacados del momento. "Recuerdo que vino un autobús lleno de marchadores desde Cataluña.» ${ }^{27}$

En ese mismo año 83 el club no tenía presidente y Jaime Gila aunque estaba trabajando en Ayllón de profesor de Educación Física, decidió tomar la presidencia, con la finalidad de que el club siguiera formando atletas.

«Yo recuerdo que le decía a mi Junta Directiva, que no iba a estar, pero ellos decían que presidentes no querían ser. Y ellos me respondian: tú no te preocupes que nosotros hacemos todo. $Y$ estuve varios años de presidente, pero poco más que de figurín. ${ }^{28}$

Aquellos años, como Jaime reconocía fueron duros, ya que cuando iba a Segovia algunas veces recibía los reproches de algunos atletas porque les faltaba algo de material. Aunque agradeció la labor desinteresada de su junta directiva, quienes colaboraron para el funcionamiento de la entidad. "Venias y a lo mejor venias a llevarte la bronca de alguien, que si a un chico no le habéis dado un chubasquero..." 29

En el año 1988 se instaló material sintético a la pista, comúnmente llamado tartán, traído desde Alemania. En un principio solo se iba a poner en cuatro calles; pero finalmente se implanta en las ocho.

Los primeros años de los 90 conllevaron un cambio radical en la directiva del club, ya que se crearon los socios. Estos van a tener voto en las asambleas en las que se decide, por ejemplo, donde se va a invertir el dinero de la entidad. Los socios eran antiguos atletas que ya no entrenaban pero que querían aportar una pequeña cuantía económica para seguir colaborando con la entidad.

«Al final, el hacer socios, no era nada más que sacarte un poco más a nosotros mismos, ya que la mayoría de los socios del club eran atletas de aquella época, que querían colaborar de manera desinteresada con una pequeña cantidad económica el desarrollo del club. $»^{30}$

Además, en esta época se deja de competir en Madrid. Esto fue debido a que se empezó a tratar con las federaciones territoriales. Segovia pertenece a la de Castilla y León. Por tanto, ahora los desplazamientos son a Valladolid, Salamanca, Ávila...

A finales de los años 90 el C.A.J. Blume iba a ser pionero en el deporte inclusivo, ya que contaba en sus filas con un grupo de atletas con sordera. La gran implicación y buen trato que la entidad da a estos atletas hace que hace que cada año vaya aumentando su número, hasta convirtiéndose en uno de los clubs más laureados de España. El C.A.J. Blume costeaba algunos de los viajes de estos atletas y les conseguía material deportivo. La entidad estuvo muy contenta

\footnotetext{
${ }^{27}$ De entrevista con Jaime Gila ya citada.

${ }^{28}$ De entrevista con Jaime Gila ya citada.

${ }^{29}$ De entrevista con Jaime Gila ya citada.

${ }^{30}$ De entrevista con Emiliano del Caño ya citada.
} 
con ellos, ya que ayudaban al club en las ligas. Con la salida de los dos atletas sordos segovianos, se decidió que desapareciera esta sección el año 2015.

«Javier Soto posiblemente fue el mejor atleta sordo español de todos los tiempos, con excelentes resultados, tanto en competiciones con atletas oyentes, como en campeonatos internacionales para Sordos.» ${ }^{31}$

Desde el año 2012 el club ha ido fomentando diferentes actos como club-escuela. En el año 2012 se fue a los Juegos Olímpicos de Londres con un grupo de jóvenes atletas. Se crearon diferentes gymkanas para las etapas de formación del club como: la gymkana de Halloween, la gymkana de carnaval, la visita de Papá Noel, la macarronada de final de temporada, la foto de familia, la cena de navidad... Todas ello con el objetivo de crear ese ambiente familiar, alegre y de amistad que siempre ha promovido el club.

En el año 2018 falleció el presidente y entrenador de la entidad, lo que supuso un duro golpe. Posteriormente se organizó una nueva Junta Directiva con ideas renovadas, pero con la misma filosofía. Esta nueva etapa es capitaneada por Gustavo Gómez.

«Es posible que yo haya cogido la presidencia en uno de los momentos más complicados, debido a las circunstancias dolorosas el fallecimiento de Isaac. ${ }^{32}$

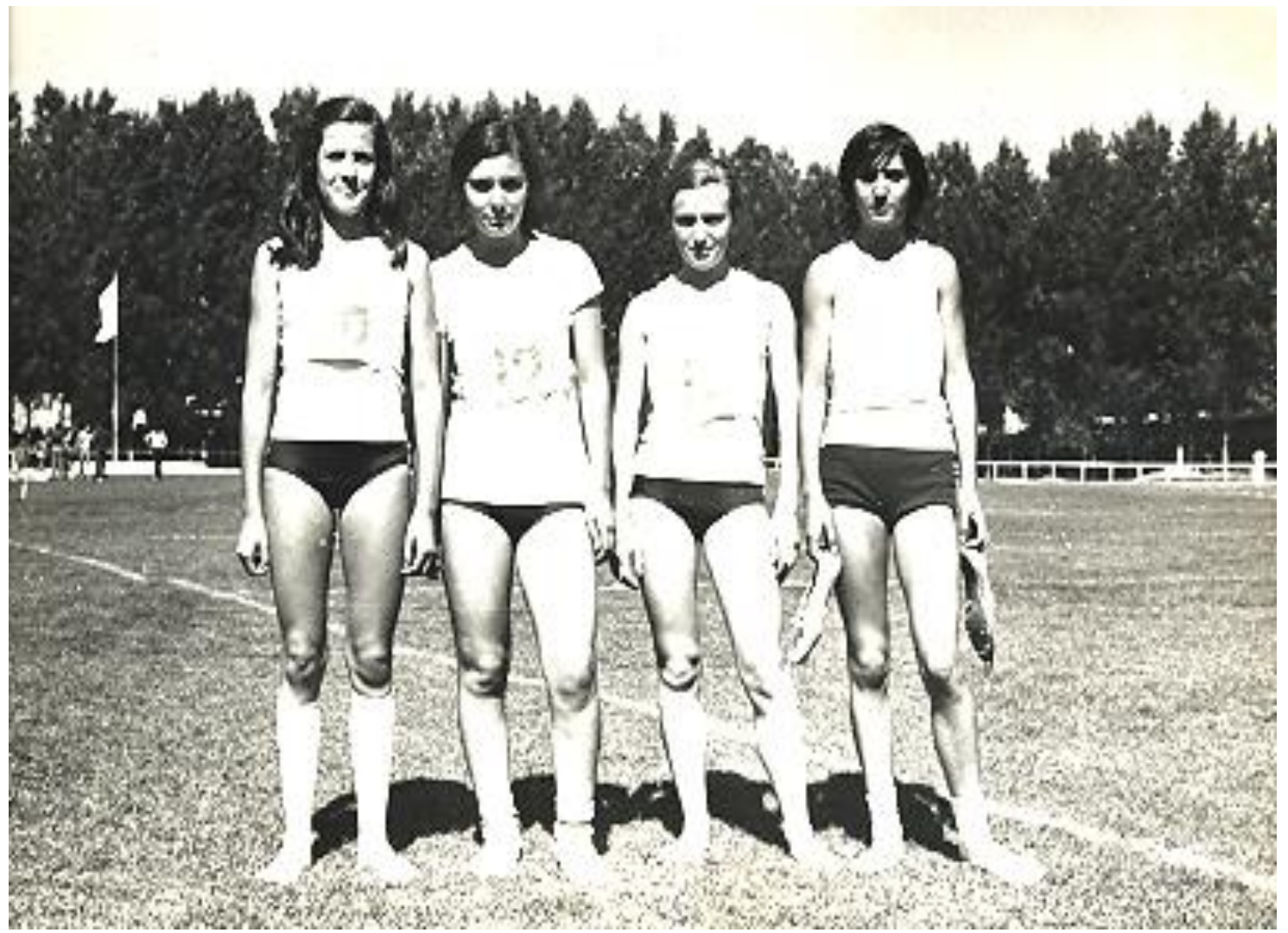

Ilustración 1: Año 1980. Record Provincial 4x400. Gema, Mercedes, Piedad y Marisa.

\footnotetext{
${ }^{31}$ De entrevista con Tomás Lorenzo (Correspondiente a su segunda etapa en la presidencia) ya citada.

${ }^{32}$ De entrevista con Gustavo Gómez ya citada.
} 
Para concluir este apartado del trabajo, procedemos a enumerar los diferentes clubs de atletismo que han ido surgiendo en la ciudad de Segovia con sus respectivas dataciones. A principios de los años 70 se creó en Segovia El Imperio; un club pequeño que contaba con grandes fondistas, que acabó por desaparecer. En el año 1986 se fundó el C.A.S. (Club Atletismo Segovia) Este club es solo de mujeres y todavía sigue en la actualidad (2020). En 1996 se creó el C.A. Velox otro equipo solo de féminas y que continúa en el presente (2020). En el año 2005 se creó el J.A.S (Juventud Atlética Segovia) entidad deportiva en la que solo hay varones y que todavía continua vigente en el 2020. Por último, se creó el Sporting cuya fundación data del año 2010. Es un equipo mixto, cuya actividad prosigue en el 2020.

\section{Patrocinadores y colaboradores de la entidad.}

En su creación el club estaba adscrito a la sección de Educación y Descanso ${ }^{33}$. De ella recibió las primeras ayudas en forma de material deportivo chándal y ropa de competición. La RFEA también colaboró durante estos primeros años con el C.A.J. Blume subvencionándole con ayudas de material deportivo como: zapatillas de clavos, jabalinas, peso, disco... Durante estos años el C.A.J. Blume no pedía cuotas a sus atletas.

«Siempre que íbamos a Madrid a competir, mandábamos un escrito a la Federación Española, solicitando subvenciones, para comprar: zapatillas de clavos, chándal, jabalinas.» ${ }^{34}$

El primer patrocinador privado con el que contó el C.A.J. Blume fue Europol S.L. Se trata de una empresa de construcción de muebles que comenzó a patrocinar el club en 1978 y se mantuvo hasta 1980.

«Siento un gran agradecimiento a Europol por su colaboración, porque era una época difícil económicamente hablando y ellos confiaron en nosotros y nos patrocinaron.» ${ }^{35}$

Tras Europol S.L. llegó en el año 1981 una oferta de un millón de pesetas del Banco Occidental. Después de varias reuniones se decidió aceptar la propuesta. Y, por tanto, el Banco Occidental pasó a ser el patrocinador principal del club hasta el año 1983.

«Estaba mi hermano trabajando en un banco llamado Occidental, aquí en Segovia, y le convencí para que me citara con el director. Cuando salí de la reunión llevaba bajo el brazo una oferta de patrocinio de un millón de pesetas.» ${ }^{36}$

Al finalizar el acuerdo con el Banco Occidental, el club fue apoyado de forma mínima por la Fundación de la Caja de Ahorros de Segovia. Aquellas ayudas de la Caja de Ahorros se extendieron hasta el año 2015.

«Después de perder el patrocino de Europol y de Banco Occidental, llegó el apoyo de la Caja de Ahorros. Este apoyo era por medio de su obra social que subvencionaba prácticamente todo tipo de actividades que se realizaran en Segovia en aquellos años. ${ }^{37}$

Con Tomás Lorenzo en la presidencia se consiguió que la Fundación de la Caja de Ahorros llegara a subvencionar al club con cifras aproximadas a los 18.000€. Además, en aquella

\footnotetext{
${ }^{33}$ Educación y Descanso: fue una organización española de tipo cultural y recreativo, dependiente de la Organización Sindical Española, que existió durante la época de la dictadura franquista, entre 1939 al 1977. Educación y Descanso (EyD) se dedicaba a promover y organizar todo tipo de actividades de índole cultural, artístico y deportivo. EyD fue una de las organizaciones del régimen que mayor impacto tuvo entre los trabajadores.

${ }^{34}$ De entrevista con Antonio Pinillos ya citada.

${ }^{35}$ De entrevista con Fernando Fuentetaja ya citada.

${ }^{36}$ De entrevista con Fernando Fuentetaja ya citada.

${ }^{37}$ De entrevista con Jaime Gila ya citada.
} 
época también colaboraban empresas como: Restaurante La Portada, Hotel Puerta Segovia, Ópticas Damián, Gestoría Cuesta, La Postal, Azulejos Tabanera...

«Cuando yo llegué a la presidencia la Caja nos subvencionaba con 50.000 pesetas y tras varias reuniones se consiguió llegar a los 18.000€.»

En la presidencia de Gustavo Gómez las ayudas de las empresas privadas eran mínimas debido a la situación económica del país. La ayuda más destacada de las empresas privadas segovianas provenía de BigMat Tabanera.

«BigMat Tabanera se trata de una empresa de construcción y colabora con el equipo dentro de sus posibilidades. Todo el mundo conoce la situación de la construcción en estos momentos en España, por consiguiente, ayudan en lo que pueden.» ${ }^{38}$

Otras subvenciones que ha recibido el C.A.J. Blume durante toda su historia han sido las obtenidas de las administraciones públicas: Ayuntamiento de Segovia y Diputación Provincial; además de la creación de socios a principios de los 90, ya citada, la entidad comenzó a solicitar a los atletas una pequeña cuantía económica anual, desde finales de los años 80 .

«Las subvenciones del Ayuntamiento o de la Diputación eran las mismas que en años anteriores, lo que pasa es que la "tarta" se reparte entre un mayor número de clubs.»39

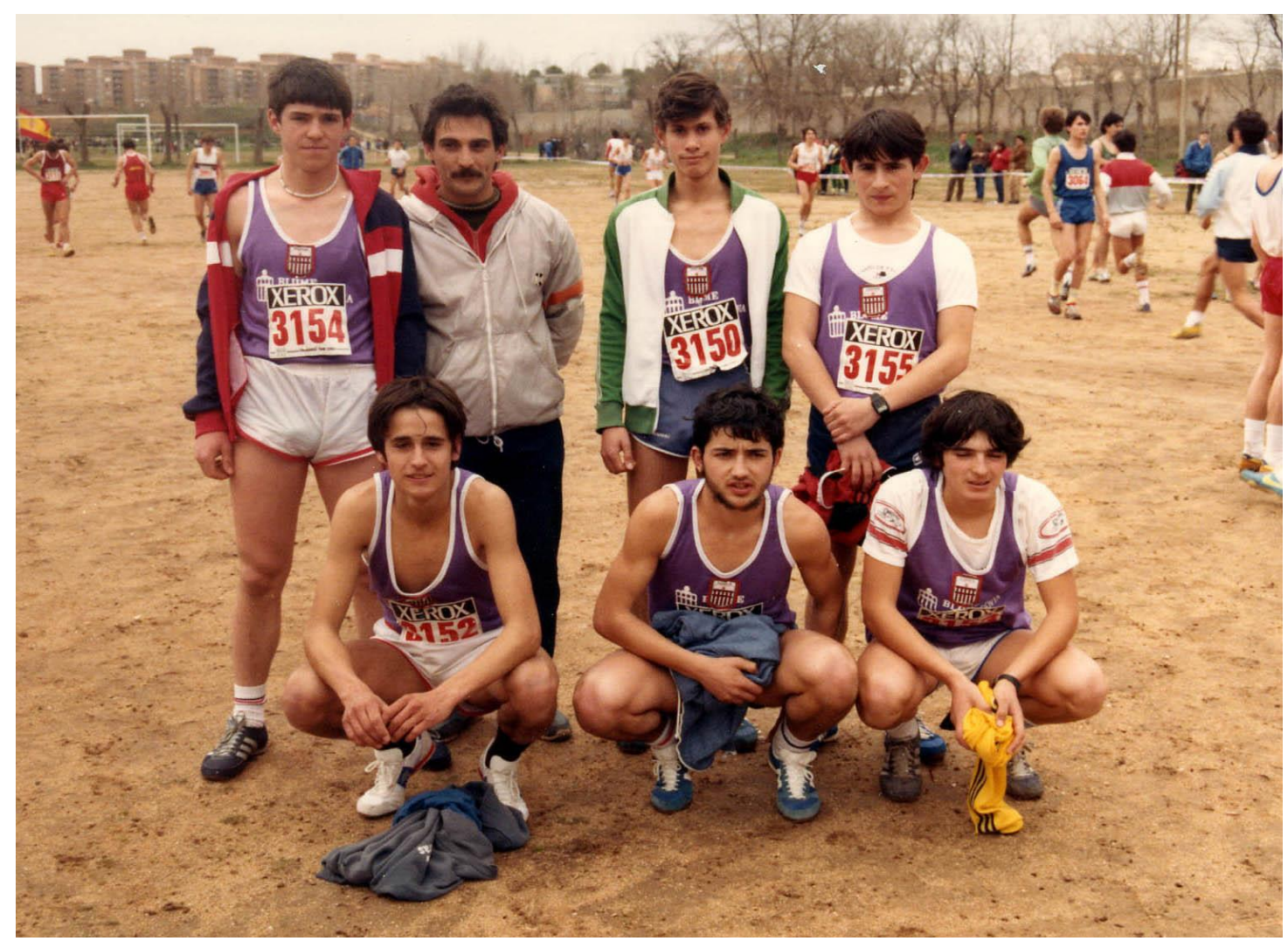

Ilustración 7: Campeonato de España Juvenil, febrero 1985. Disputado en Toledo. Medalla de Bronce por equipos. Fila de arriba: José Ignacio Fernández Gaitero (Riaza), Isaac Sastre, Juan Jesús Pastor y Mariano Castro. Fila de Abajo: Galindo, Víctor López y Pedro Ruiz (Riaza). *Este mismo equipo al año siguiente consiguió el Campeonato de España por club Juvenil.

\footnotetext{
${ }^{38}$ De entrevista con Gustavo Gómez ya citada.

${ }^{39}$ De entrevista con Gustavo Gómez ya citada.
} 


\section{Repercusión en los medios de comunicación}

Los medios de comunicación segovianos siempre han difundido los resultados obtenidos por el C.A.J. Blume. Para ayudar a difundir las noticias desde el año 1970 el club ha tenido un departamento de prensa que ha elaborado las noticias, que después han sido publicadas por la prensa segoviana.

Antonio Pinillos recuerda que gracias a la prensa se empezó a dar conocer el club, estos servicios los prestaba El Adelantado de Segovia y Radio Segovia. «Recuerdo a Castrillo, un locutor de Radio Segovia que si se interesó en difundir información sobre el club: resultados, noticias y entrevistas.» ${ }^{40}$

Con la presidencia de Fernando Fuentetaja el C.A.J. Blume creó una revista de tirada trimestral con la finalidad de llegar a más personas. Estas revistas se realizaban en una multicopista y salían 5 ó 6 ejemplares.

Emiliano de Caño y Tomás Lorenzo, en su segunda etapa como presidente, recuerdan que llegó a la ciudad un nuevo periódico El Diario de Castilla.

«Me gustaría resaltar la labor de un periodista en particular, Chicho. Este realizaba un seguimiento de los atletas del club, sabía a qué pruebas habías ido o cuales eran los objetivos de tu temporada.» ${ }^{41}$

Tomás Lorenzo en colaboración con Radio Segovia, llegó a narrar en abierto la disputa de alguna carrera. Esta narración se podía llevar a cabo gracias a una llamada telefónica al móvil de Tomás Lorenzo, el cual se encontraba en el lugar donde se disputaba la prueba.

«He retransmitido en directo actuaciones de los atletas del club gracias a la colaboración de Radio Segovia y su presentador de los deportes Rivilla.» ${ }^{42}$

Durante los últimos años de la presidencia de Tomás Lorenzo y hasta Gustavo Gómez, se ha potenciado cada vez más el uso de las páginas web. El club posee una en la que se publican todas las competiciones a las que acude algún atleta del mismo. Y desde el año 2010 el club se da a conocer por las redes sociales Facebook e Instragam (2019).

«Blume es una marca que ha vendido mucho y simplemente salir en un medio de comunicación citando que un atleta del C.A.J. Blume ha cosechado un éxito tiene más notoriedad que probablemente la de otros atletas de otros clubes.» ${ }^{43}$

\section{Repercusión en la sociedad segoviana}

Si los medios de comunicación han tenido un trato optimo con el C.A.J. Blume, la sociedad segoviana reconoce a la entidad por sus más de 50 años de convivencia; por sus logros, que son amplios y de gran relevancia nacional e internacional; también por los innumerables eventos sociales que ha promovido y organizado; y el más importante, las opiniones positivas sobre el ambiente familiar y saludable que promueve el club.

«Lo que hizo crecer al club en apenas 3 años fue las gentes de Segovia, que hablaban y hablaban bien sobre C.A.J. Blume, su amistad y ambiente alegre.» ${ }^{44}$

\footnotetext{
${ }^{40}$ De entrevista con Antonio Pinillos ya citada.

${ }^{41}$ De entrevista con Emiliano del Caño ya citada.

${ }^{42}$ De entrevista con Tomás Lorenzo (Correspondiente a su segunda etapa en la presidencia) ya citada.

${ }^{43}$ De entrevista con Gustavo Gómez ya citada.

${ }^{44}$ De entrevista con Antonio Pinillos ya citada.
} 


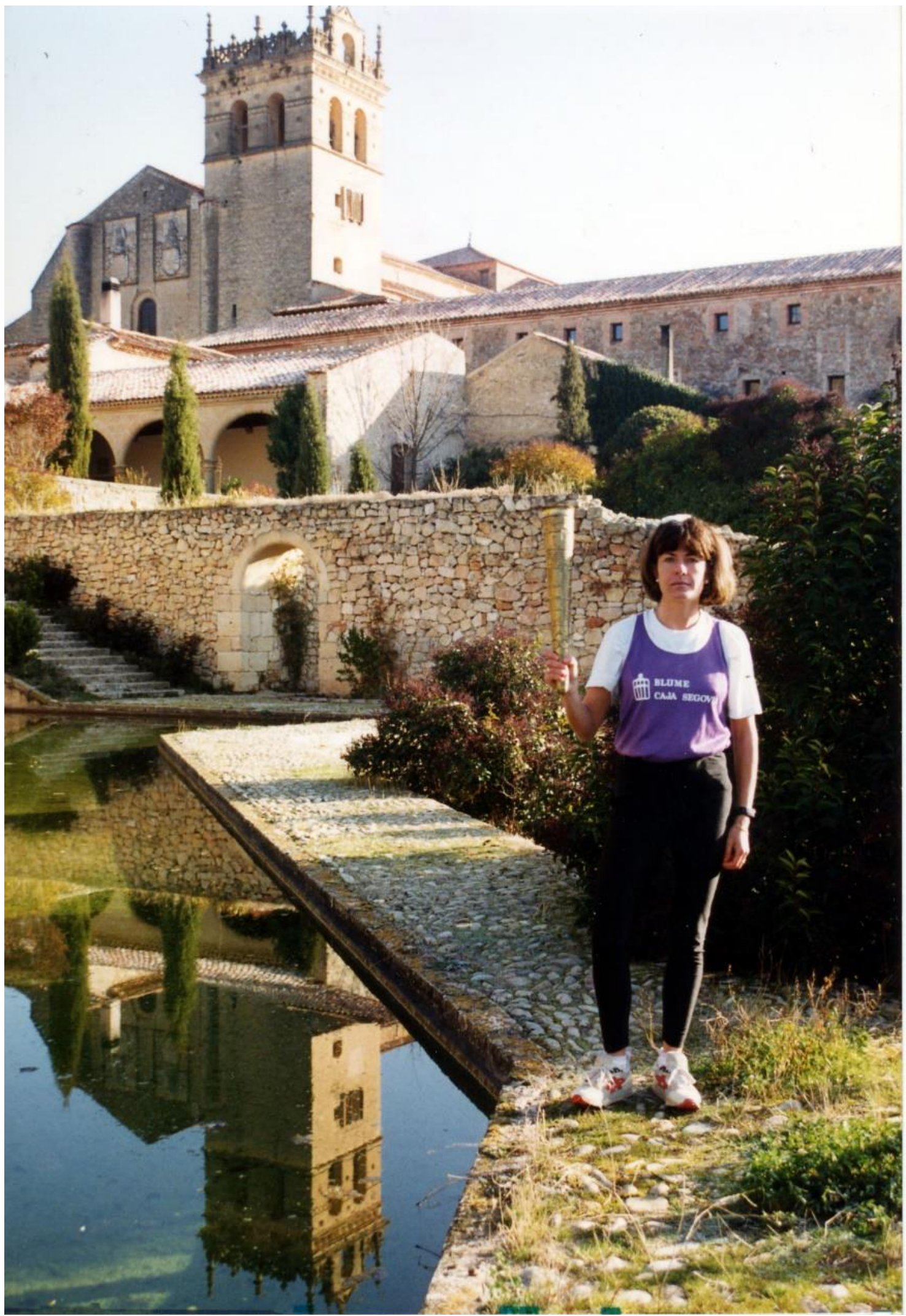

Ilustración 8: Gema Gómez portadora de la Antorcha Olímpica de Barcelona en el año 1992. En el Monasterio del Parral de Segovia. 
En apenas 3 años el club pasó de contar con tan solo 15 atletas masculinos a tener alrededor del medio centenar, reuniendo atletas de ambos sexos. Durante la primera época de Tomás Lorenzo en la presidencia, la sociedad segoviana acudía el 25 de diciembre por la tarde a ver el Trofeo Navidad.

«La repercusión social del Trofeo Navidad era buena porque participábamos en ella todos los atletas del club, e iba gente a verlo, se hacía de una forma bastante ceremonial.» ${ }^{45}$

Durante la presidencia de Fernando Fuentetaja se cosecharon importantes resultados y por consiguiente el club empezó a tener mayor transcendía social. "En esta época la gente comienza a conocer de las hazañas de Francisco Guerra, Vicente Polo.... ${ }^{46}$

Emiliano del Caño resaltaba que en su época comenzó la gente a practicar más atletismo en especial la carrera a pie. En aquel momento fue cuando se empezaron a organizar carreras populares.

«Se comenzó poco a poco a aumentar la participación en las pruebas que organizaba el club, como la San Silvestre Segoviana.» ${ }^{47}$

Pero, si hay algo que puede sorprender es que la popularidad de algunos atletas del C.A.J. Blume, era casi mejor fuera de Segovia que en la propia ciudad. Algunos casos fueron Javier Moro, Francisco Guerra, los cuales eran admirados en otras ciudades de España.

«La repercusión en Segovia fue buena. Y aún mejor fuera de la capital. Los atletas del C.A.J. Blume eran muy reconocidos no solo a nivel competitivo, sino también por sus valores. ${ }^{48}$

Para Gustavo Gómez el trato de la sociedad segoviana es inmejorable. La ciudad se volcó con algunos de los actos organizados durante el 50 aniversario del club.

«El C.AJ. Blume ha sido un referente, prueba de ello fue la cena del 50 aniversario donde se juntaron más de 200 personas. Eso demuestra todo lo que se ha hecho a lo largo de estos años para sociedad segoviana. ${ }^{49}$

\subsection{Eventos del C.A.J. Blume para acercar el atletismo a la sociedad}

Uno de los pilares del club, como ya ha sido citado, era dar a conocer el atletismo a la sociedad segoviana. Con esa finalidad el club creó diferentes eventos deportivos a lo largo de su historia. A continuación, se enumeran los más relevantes: Trofeo Navidad (1971 al 1977), Trofeo Agustín Fernández (1969 al 1971), San Silvestre Segoviana (1978 al 2011), Trofeo Amistad (1986 al 2016), Milla José Luis Herrero (1993 hasta 2011), Trofeo 50 Aniversario (2017), Trofeo Memorial Isaac (2019 y 2020).

\footnotetext{
${ }^{45}$ De entrevista con Tomás Lorenzo (Correspondiente a su primera etapa en la presidencia) ya citada.

${ }^{46}$ De entrevista con Fernando Fuentetaja ya citada.

${ }^{47}$ De entrevista con Emiliano del Caño ya citada.

${ }^{48}$ De entrevista con Tomás Lorenzo (Correspondiente a su segunda etapa en la presidencia) ya citada.

${ }^{49}$ De entrevista con Gustavo Gómez ya citada.
} 
El C.A.J. Blume ha organizado otras pruebas; pero de menor calado en la sociedad segoviana, como la organizada en el año 1968 en las pistas de baterías bajo la presidencia de Antonio Pinillos. "Una vez, logramos hacer una prueba en Baterías que era un poco más decente. ${ }^{50}$

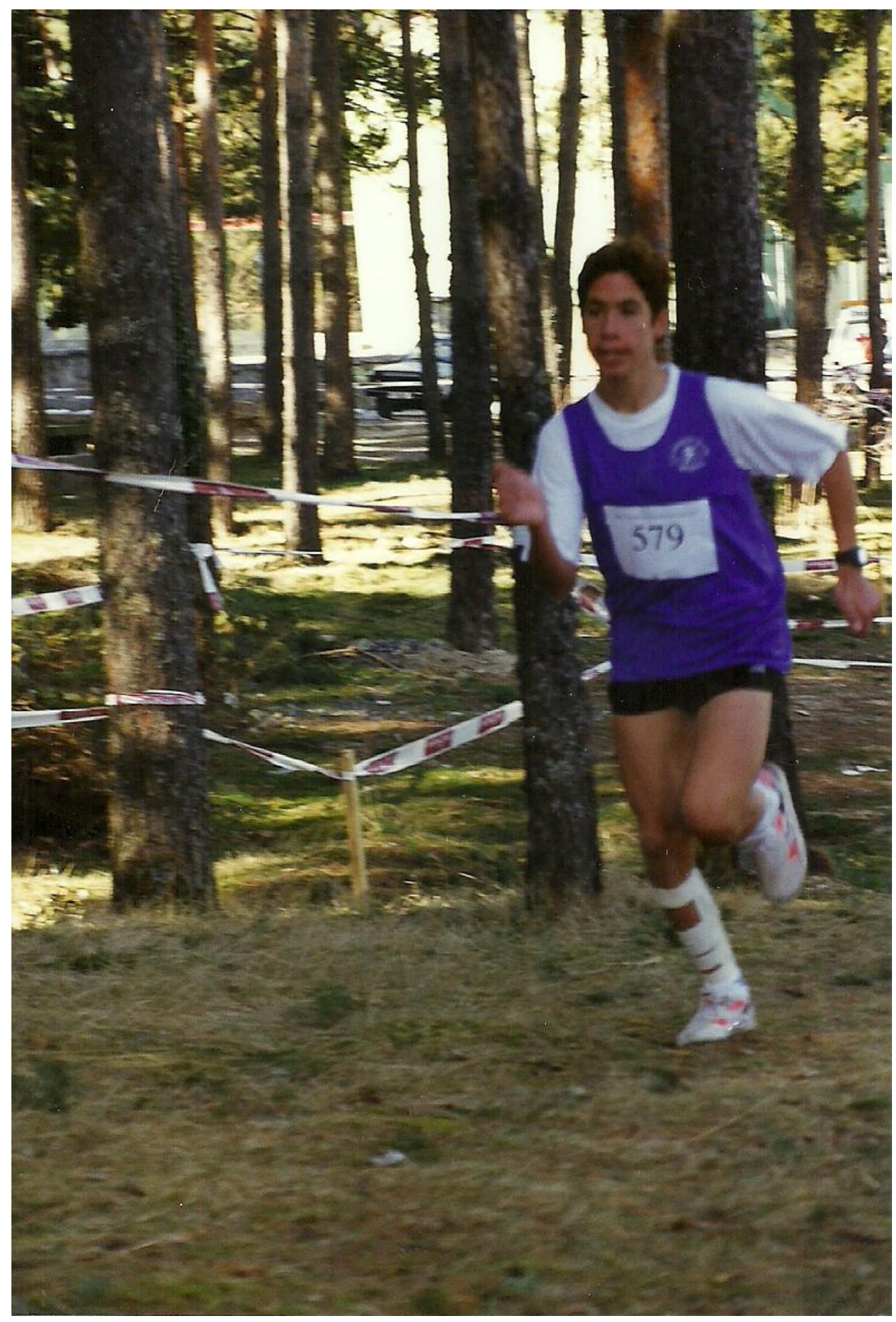

Ilustración 92: Javier Guerra, dando sus primeros pasos atléticos en el C.A.J. Blume. 1997. Atleta con dos mínimas para los Juegos Olímpicos de Rio y Tokio.

${ }^{50}$ De entrevista con Antonio Pinillos ya citada

Citius, Altius, Fortius Volumen 13 ne 2. Noviembre, 2020. ISSH. 2340-9886.

http://doi.org/10.15366/eitius2020.13.2 
La primera prueba de repercusión social fue el trofeo Navidad. Esta prueba era una carrera de unos $5 \mathrm{~km}$ en ruta, que se celebraba el día 25 de diciembre por la tarde. En ella han participado atletas segovianos y de otras provincias limítrofes a Segovia, como, por ejemplo: Madrid, Valladolid, Salamanca... El nivel de participación rondaba el medio centenar.

\section{«La carrera transcurría por: Fernández Ladreda (actual Avenida Acueducto), Camino Nuevo (actual Paseo Ezequiel González) y bajada por Santo Tomás.» ${ }^{51}$}

El Trofeo Navidad cambió de fecha y de nombre. Se pasó a denominar San Silvestre Segoviana y se comenzó a disputar la noche del 31 de diciembre del 1978. Su primera edición no superó la treintena de participantes, pero con el paso de los años llegó a reunir en su última edición en el año 2011 a más de 3.900 atletas. Aquella progresión fue debida al buen hacer de la entidad que siempre apostó por esta carrera. Para Tomás Lorenzo:

«En los últimos años de mi presidencia la sociedad segoviana se volcaba con la carrera llegando a tener 3.900 inscritos. 2100 atletas en la carrera sénior y con las calles abarrotadas para ver pasar a los corredores, lejos quedaban los años en los no se llegaba al medio centenar de participantes. ${ }^{52}$

A la vez que evolucionaba la carrera más laureada de Segovia, La San Silvestre Segoviana, el club siguió organizando trofeos como el Amistad. Para Emiliano del Caño era el trofeo que más le gustaba, en virtud de su componente lúdico de coincidir con gente de otras épocas del club y pasar una tarde con amigos practicando el deporte que les gustaba. Esta prueba tenía unas reglas poco habituales en el mundo del atletismo.

«Por cada año que cumplías demás por encima de los treinta sumabas un punto. Tenías que hacer una serie de pruebas: 100, longitud, peso y un mil. Y el que sumase más puntos, teniendo en cuenta el coeficiente de edad era el ganador. ${ }^{53}$

En el año 1993 se creó la milla José Luis Herrero, que se celebraba en la avenida Fernández Ladreda, la actual Avenida Acueducto. Se solía realizar a finales de octubre, como apertura de la temporada atlética.

«La entidad tenía mucho cariño a esta prueba y pese a que económicamente era inviable, el C.A.J. Blume se sentía con el deber y obligación de llevarla a cabo» ${ }^{54}$

Para terminar, este apartado se rescatan los datos del trofeo 50 aniversario del C.A.J. Blume y de su transformación al Memorial Isaac Sastre. El primero se creó para conmemorar el 50 aniversario de la entidad. Este trofeo se organizó el 17 de mayo del 2017. Se celebró en la pista y en él se realizaron pruebas de todas las especialidades atléticas. Su nivel de participación fue elevado.

«Creo que fue la manera ideal y correcta de celebrar el 50 aniversario del club, potenciando y celebrando sus 50 años a través de una prueba de pista federada, debidamente reglamentada. ${ }^{55}$

Tras el fallecimiento de Isaac Sastre, la junta directiva decidió homenajearle con una prueba en pista. El Memorial Isaac Sastre, cuya primera edición se disputó el 12 de mayo del 2019 contó con una gran participación: más de 250 atletas admitidos. Un número muy elevado para ser una prueba en pista. Este trofeo fue divulgado por los medios de comunicación y el Ayuntamiento de Segovia. Y al que acudió el presidente de la RFEA, Raúl Chapado.

\footnotetext{
${ }^{51}$ De entrevista con Tomás Lorenzo (Correspondiente a su primera etapa en la presidencia) ya citada.

${ }^{52}$ De entrevista con Tomás Lorenzo (Correspondiente a su segunda etapa en la presidencia) ya citada.

${ }^{53}$ De entrevista con Gustavo Gómez ya citada.

${ }^{54}$ De entrevista con Tomás Lorenzo (Correspondiente a su segunda etapa en la presidencia) ya citada.

${ }^{55}$ De entrevista con Gustavo Gómez ya citada.
} 
«Isaac nos explicaba que como club teníamos una obligación moral de acercar a la sociedad Segoviana el atletismo, a través de una prueba federada debidamente reglamentada.» ${ }^{56}$

Todos estos eventos han tenido una gran repercusión, tanto en los medios de comunicación segovianos, como un gran impacto en la sociedad segoviana.

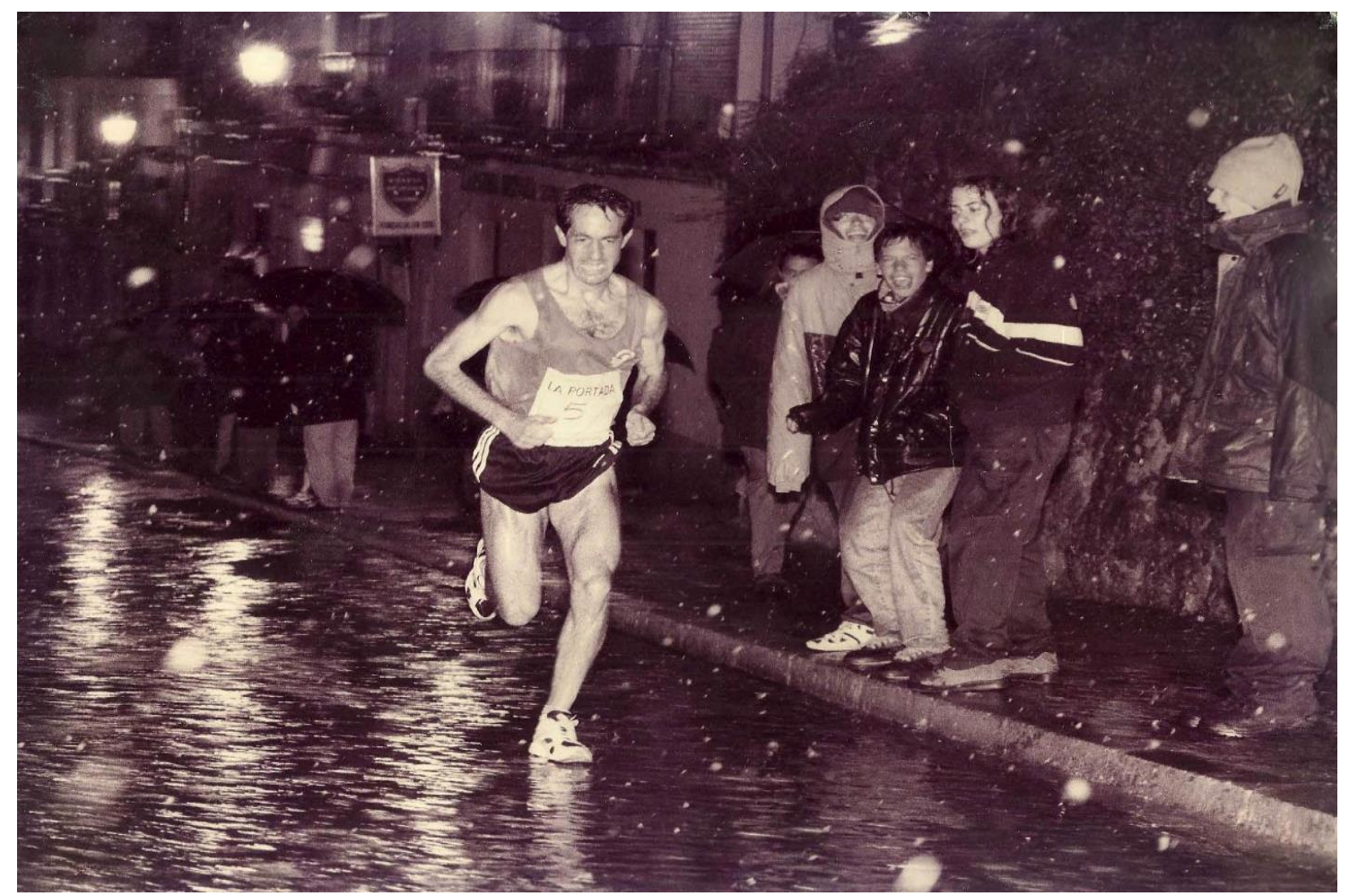

Ilustración 10: Francisco Guerra, En la San Silvestre del Año 1999. Subiendo la Cuesta de San Juan.

\section{Logros del club durante sus más de 50 años.}

En este apartado se van a destacar algunos de los logros más relevantes del C.A.J Blume durante sus más de 50 años.

Por la entidad han pasado o se han formado hasta 34 atletas internacionales, los más destacados han sido: Agustín Fernández (dos participaciones en Juegos Olímpicos) y Javier Guerra (dos mínimas para los Juegos Olímpicos). El club ha conseguido varios títulos nacionales, tanto a nivel individual, como grupal. El número de medallas en Campeonatos Nacionales han sido alrededor de 80 metales. Además, hasta tres atletas llegaron a tener tres récords nacionales. Jesús San Isidro el de 1000 metros lisos en el año 1972. Julio de Andrés Sanz en el año 1984 en la prueba de $5000 \mathrm{ml}$ marcha pista cubierta y Pedro Pablo del Barrio en el año 1987 en la distancia de 100 metros lisos. A nivel europeo y Mundial el club ha llegado a obtener varias medallas en la categoría de veteranos. En atletismo para sordos el club obtuvo importantes resultados en la figura de Javier Soto, con récords nacionales, europeos y Mundiales. Varias medallas a nivel: Nacional, Europeo, Mundial y Sordolimpiadas. Por último, cuatro atletas que han militado en el equipo han portado la Antorcha Olímpica a su paso por Segovia en el año 1992 (Agustín Fernández, Francisco Guerra, Jaime Peñas y Gema Gómez).

\section{Conclusiones y reflexiones de los presidentes del C.A.J. Blume}

\footnotetext{
${ }^{56}$ De entrevista con Gustavo Gómez ya citada.
} 
Antonio Pinillos se siente orgulloso de haber colaborado a que se haga atletismo en Segovia y, sobre todo, a que el club que ellos crearon, allá por el año 1966 siga potenciando la práctica atlética en la ciudad.

«No te lo planteas, piensas en algún momento que eres imprescindible, pero a los 3 años vi que había cantera y que podía durar, pero nunca que iba a llegar a 50 años. ${ }^{57}$

Para Fernando Fuentetaja, Jaime Gila, Emiliano del Caño y Tomás Lorenzo el C.A.J. Blume les ha dado muchas más alegrías que quebraderos de cabeza, pese a que ser presidente de una entidad deportiva conlleva buenos y malos momentos. Todos ellos, se quedan con los momentos de felicidad vividos con sus amigos practicando su pasión: el atletismo.

«Me siento orgulloso de haber sido del Blume y sentirme parte de ello, todavía hoy soy del Blume, aunque no tenga relación directa con el club.» ${ }^{58}$

El futuro del C.A.J. Blume será lo que Gustavo Gómez y su junta directiva hagan durante los próximos años, por eso algunas de sus metas serán que el Memorial Isaac Sastre se afiance a nivel regional. Y el otro pilar será seguir luchando por recuperar la San Silvestre Segoviana.

«La junta directiva tenía la obligación moral de seguir luchando por intentar recuperar una prueba que es suya, Hay muchas generaciones atrás que han luchado por esta prueba.» ${ }^{59}$

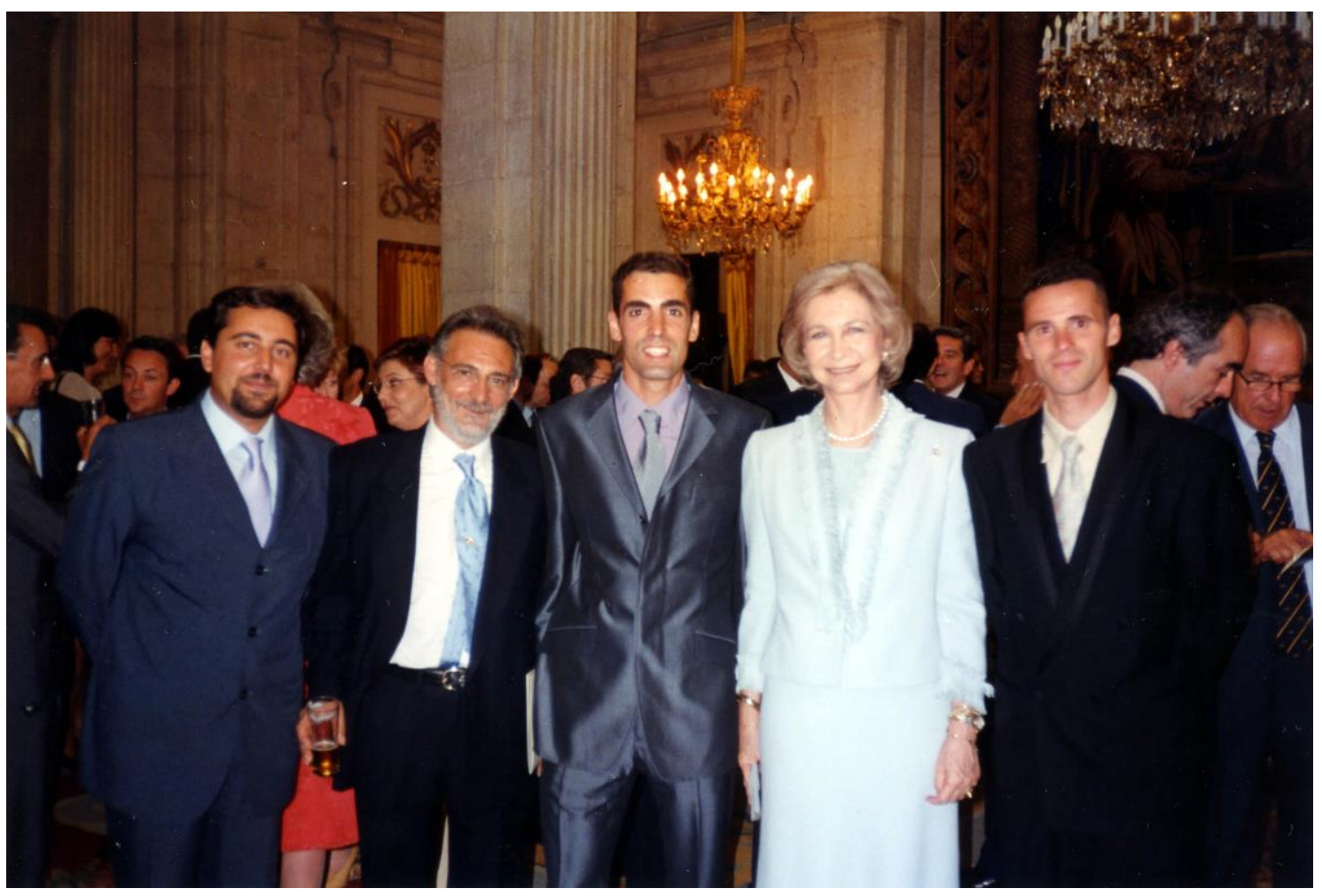

Ilustración 11: ----, Isaac Sastre, Javier Soto, La Reina Sofía, ----. En la recepción Real al equipo para Sordos Español. Año 2008

\footnotetext{
${ }^{57}$ De entrevista con Antonio Pinillos ya citada.

${ }^{58}$ De entrevista con Tomás Lorenzo (Correspondiente a su primera etapa en la presidencia) ya citada.

${ }^{59}$ De entrevista con Gustavo Gómez ya citada.
} 


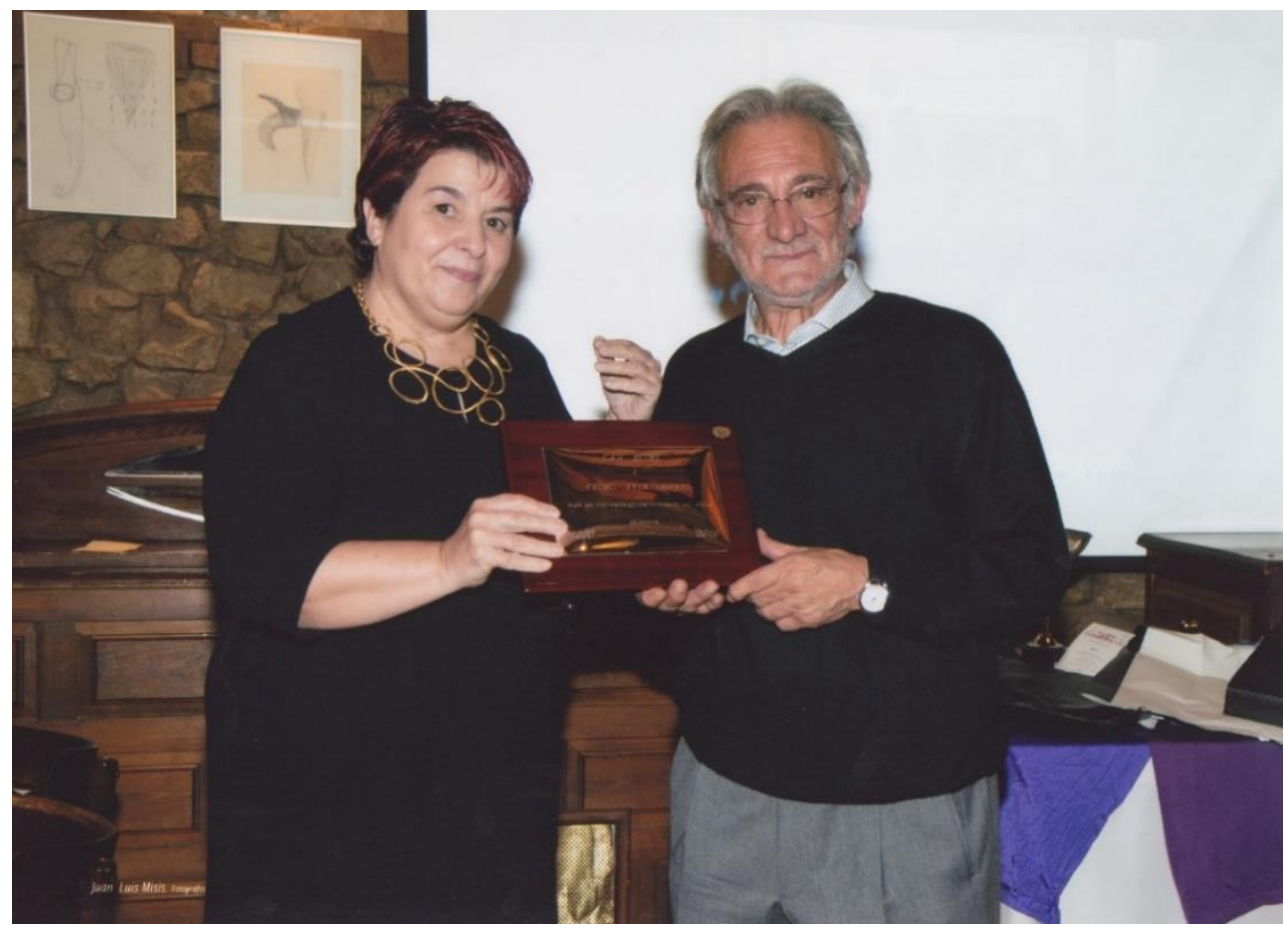

Ilustración 32: La alcaldesa Clara Luquero con Isaac Sastre, en el año 2016, durante la celebración de la cena del 50 Aniversario del Club. La alcaldesa entrega al presidente de la entidad una placa conmemorativa. (Restaurante La Portada del Medio Día)

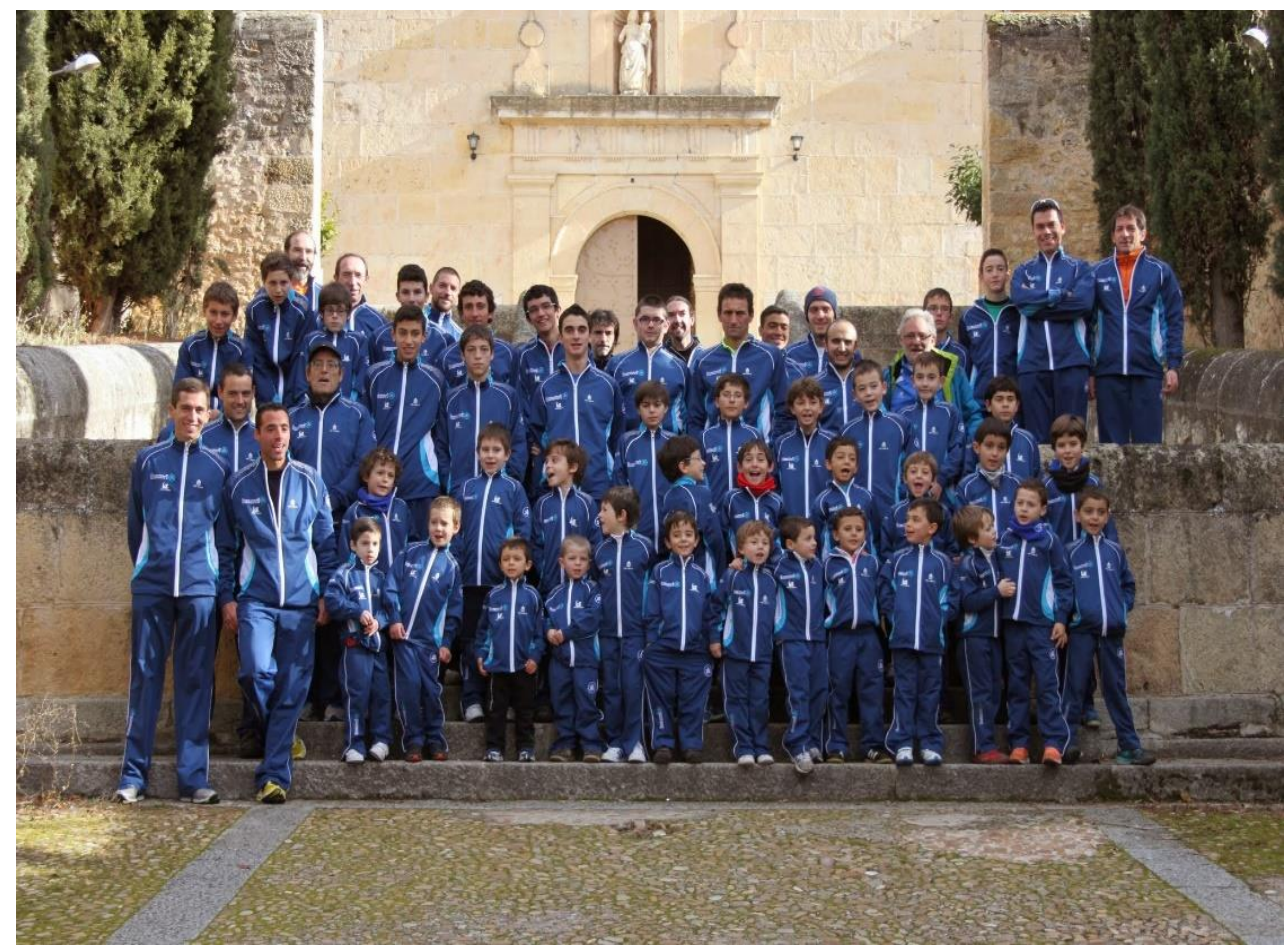

Ilustración 43: Foto de Equipo año 2013. En la escalinata de Los Carmelitas (Segovia). Fila de abajo: Gustavo, Jorge, Aarón, Eduardo, Pablo, Rubén, Nicolás, Álvaro, Guillermo, Adrián, Samuel, Marco, Ángel, Álvaro, Rubén. Fila 2. Iván, Alberto, Manuel, Juan, Miguel, Alejandro, Daniel, Héctor, Mauro. Fila 3: Nacho, José Ignacio, Jesús, Guillermo, Marcos, Segismundo, Iván y Lucas. Fila 4: Fernando, Miguel, Mario, Souliman, Mario, Félix, David, Fernando, Moha, Isaac. Fila 5: Alberto, Chema, Andrés, Rubén, Jorge, David, Ángel, Nick, Ibrahim, Gonzalo, José Luis, Pablo, Paco y Valentín. 


\section{Fuentes y Bibliografía}

\subsection{Fuentes Orales}

Para la realización del presente trabajo han sido efectuadas por el autor siete entrevistas a las siguientes fuentes primarias:

- Antonio Pinillos Grande, presidente, entrenador y atleta del club desde el año 1966 hasta 1969. Entrevista celebrada en Segovia el día 1 de agosto del 2019. Referida el 15 de agosto del 2019.

- Tomás Lorenzo (Correspondiente a su primera etapa en la presidencia), presidente y atleta del club desde el año 1970 hasta 1973. Entrevista celebrada en Segovia 26 de septiembre del 2019. Referida el 9 de octubre del 2019.

- Fernando Fuentetaja, presidente y atleta del club desde el año 1979 hasta 1981. Entrevista celebrada en Segovia el día 2 de octubre del 2019. Referida el 19 de octubre del 2019.

- Jaime Gila, presidente, entrenador y atleta del club desde el año 1983 hasta 1986. Entrevista celebrada en Segovia el día 28 de octubre del 2019. Referida el 9 de noviembre del 2019.

- Emiliano del Caño, presidente, entrenador y atleta del club desde el año 1993 hasta 1997. Entrevista celebrada en Segovia el día 2 de enero del 2020. Referida el 10 de enero del 2020.

- Tomás Lorenzo (Correspondiente a su segunda etapa en la presidencia), presidente y atleta del club desde el año 1998 hasta 2011. Entrevista celebrada en Segovia 26 de septiembre del 2019. Referida el 9 de octubre del 2019.

- Gustavo Gómez, presidente y atleta del club desde el año 2019 hasta 2020. Entrevista celebrada en Segovia el día 2 de noviembre del 2019. Referida el 11 de noviembre del 2019.

\subsection{Fuentes Hemerográficas}

— «Las pistas se caen a cachos». Diario El Adelantado de Segovia. 1 de Junio 2019.

— «En el recuerdo». Diario El Adelantado de Segovia. 15 de Mayo 2019.

— «La recompensa del éxito». Diario El Adelantado de Segovia. 3 de Febrero 2017.

— «La Nochebuena se cita con la historia». Diario El Adelantado de Segovia. 27 de Diciembre 2016.

— «El adiós a Isaac Sastre». Diario El Adelantado de Segovia. 20 de Abril 2018.

— «Más de 200 atletas rinden homenaje a Isaac Sastre». Diario El Adelantado de Segovia. 12 de Mayo 2019.

— «El Blume vive su fiesta». Diario El Adelantado de Segovia. 13 de Noviembre 2016.

- «El club Joaquín Blume celebra su 50 aniversario y el XXX Trofeo Amistad». Diario El Adelantado de Segovia. 29 de Septiembre 2016. 
— «L'enfant terrible del PSOE». Diario El Adelantado de Segovia. 3 de Diciembre 2014.

- «Los infantiles del Blume, campeones autonómicos». Diario El Adelantado de Segovia. 21 de Febrero 2013.

— «Recepción a Javier Soto». Diario El Adelantado de Segovia. 24 de Enero 2013.

- «Pablo Pérez: "El organizador histórico de la 'San Silvestre' debe ser quien la lleve a cabo"». Diario El Adelantado de Segovia. 17 de Noviembre 2012.

- «Isaac Sastre cree que la 'Carrera Fin de Año' incumple la ley de patentes». Diario $E l$ Adelantado de Segovia. 16 de Noviembre 2012.

— «El Blume no se ha presentado al concurso de la San Silvestre». Diario El Adelantado de Segovia. 7 de Noviembre 2012.

- «El futuro de la San Silvestre Segoviana se decide hoy». Diario El Adelantado de Segovia. 31 de Octubre 2012.

— «36 años haciendo amigos». Diario El Adelantado de Segovia. 27 de Octubre 2012.

— «El Ayuntamiento deniega al Blume la organización de la Milla José Luis Herrero». Diario El Adelantado de Segovia. 23 de Octubre 2012.

— «El PP se opone a la decisión de quitarle la San Silvestre al Blume». Diario El Adelantado de Segovia. 10 de Octubre 2012.

- «Tomás Lorenzo: "Es un disparate lo que ha hecho el Ayuntamiento con la San Silvestre"». Diario El Adelantado de Segovia. 27 de Septiembre 2012.

— «El Blume y el Velox, en los Juegos Olímpicos». Diario El Adelantado de Segovia. 11 de Agosto 2012.

— «Los clubes Blume y Velox premiaron a sus atletas más destacados del año». Diario $E l$ Adelantado de Segovia. 9 de Diciembre 2011.

— «El Trofeo de La Amistad del Club Atlético Joaquín Blume cumple veinticinco años». Diario El Adelantado de Segovia. 29 de Octubre 2011.

— «Diego Cebrián, cuarto en los 1.500 del Trofeo Ana Pérez de atletismo en pista». Diario El Adelantado de Segovia. 15 de Mayo 2009.

- «Javier Soto logró la mínima para las Olimpiadas para sordos de Taipei». Diario El Adelantado de Segovia. 14 de Mayo 2009.

— «Trofeo 50 Aniversario Club Atlético "Joaquín Blume”». Diario IMDSG. 5 de Mayo 2017.

— «Club de Atletismo Joaquín Blume 50 años de historia». Diario El Acueducto2. 12 de Noviembre 2016.

— «Club de Atletismo Joaquín Blume». Diario Segovia al día. 14 de Mayo 2009.

- «Los atletas sordos del Blume Caja Segovia despuntan en el nacional». Diario El Norte de Castilla. 28 de Mayo 2008. 
— «Javier Soto, campeón de España en los 1.500 para sordos». Diario El Norte de Castilla. 4 de Julio 2012.

— «Recepción al Club Atlético Blume». Diario El Día de Segovia. 7 de Octubre 2016.

— «Javi Soto, campeón de España de 1.500 m.l. para sordos». Diario Zoquejo. 28 de Mayo 2013.

— RFEA Consulta de resultados consultado el 10/02/2020 en https://www.rfea.es/

- FETACYL Consulta de atletas consultado el 12/02/2020 en https://www.fetacyl.org/

- WEB del Club Atlético Joaquín Blume. Consultado el 8/02/2020 en http://atletismoblume.com/

- Atleta Javier Soto Rey consultado el 14/02/2020 en https://www.javiersotorey.com/

\subsection{Bibliografía}

- Comité Olímpico Internacional (2015). Olympic charter. Lausanne Switzerland. Consultado el 12/02/2016 en https://www.um.es/documents/933331/0/CartaOlimpica.pdf/8c3b36b2-11a2-4a77-876a$41 \mathrm{ae} 33 \mathrm{c} 4 \mathrm{a} 02 \mathrm{~b}$

- Fazio Vengoa, H. (1998). La historia del tiempo presente: una historia en construcción p.52. Historia Crítica, 17, 47-57. https://doi.org/10.7440/histcrit17.1998.04

- Gamboa, A (2004). Historia del presente: estado de la cuestión y conceptualización. HAOL, (3), 101-116. Universidad de Los Andes, Chile.

- Hammer, D. y Wildavsky, A. (1990). La entrevista semi-estructurada de final abierto. Aproximación a una guía operativa. Historia y Fuente Oral, 4, 23-61.

- Martínez Gorroño, M. E. (1996). Metodología y fuentes en el estudio del exilio español en Colombia a consecuencia de la guerra civil 1936-1939. En Trujillano Sánchez J. M. y Díaz Sánchez P. Actas y Jornadas Historia y Fuentes orales-testimonios orales y escritos (pp. 253-258). Ávila, España: Fundación Cultural Santa Teresa. 